\title{
Redes sociais nos cuidados paliativos: uma revisão integrativa da literatura
}

\author{
Cristine Gabrielle da Costa dos Reis ${ }^{1}$, Carmen Leontina Ojeda Ocampo \\ Moré $^{2}$, Scheila Krenkel ${ }^{3}$, Marina Menezes ${ }^{4}$ \\ Universidade Federal de Santa Catarina-Brasil ${ }^{1,2,4}$, \\ Familiare Instituto Sistêmico-Brasil ${ }^{3}$
}

O presente trabalho objetivou analisar as características das funções dos membros das redes sociais configuradas em torno de familiares de pacientes em Cuidados Paliativos. As bases de dados consultadas foram PsycINFO, Web of Science e Scopus, sobre artigos publicados na última década. Considerando descritores específicos foram selecionados 30 artigos que respondiam ao objetivo proposto. Os resultados evidenciaram: a) predomínio de estudos qualitativos, b) percepçóes ambivalentes dos cuidadores com relação ao cuidado ofertado pelo suporte social/institucional e pelas redes familiares, c) presença de sentimentos de exaustão e gratificação, assim como de ansiedade e depressão durante o processo de cuidado. Constatou-se a necessidade produção de conhecimento no contexto dos Cuidados Paliativos, no Brasil e demais países da América Latina relacionados ao objetivo deste trabalho. Palavras-chave: cuidados paliativos, família, suporte social, redes sociais, revisão de literatura.

1 Mestre em Psicologia com ênfase em saúde pela Universidade Federal de Santa Maria (UFSM). Doutoranda em Psicologia pela Universidade Federal de Santa Catarina (UFSC). Endereço postal: Departamento de Psicologia, sala 07, Bloco B, Centro de Filosofia e Ciências Humanas - CFH, Universidade Federal de Santa Catarina - UFSC. Campus Reitor João David Ferreira Lima, s/n- Trindade, Florianópolis, SC - CEP: 88040-900. Contato: cristinecostareis@hotmail.com https://orcid.org/0000-0002-8935-4715

2 Mestre e doutora em Psicologia pela PUC-SP. Professora titular na Universidade Federal de Santa Catarina (UFSC) no programa de Pós-Graduaçáo e no Curso de Psicologia. Departamento de Psicologia, sala 07, Bloco B, Centro de Filosofia e Ciências Humanas - CFH, Universidade Federal de Santa Catarina - UFSC. Endereço postal: Campus Reitor João David Ferreira Lima, s/n- Trindade, Florianópolis, SC - CEP: 88040-900. Contato: carmenloom@gmail.com https://orcid.org/0000-0003-2468-8180

3 Mestre e doutora em Psicologia pela Universidade Federal de Santa Catarina (UFSC). Endereço postal: Rua Acadêmico Reinaldo Consoni, no 200, Córrego Grande, Florianópolis - SC, CEP: 88037-100. Contato: scheilakrenkel@gmail.com https://orcid.org/ 0000-0002-2976-7665

4 Psicóloga. Mestre e doutora pela Universidade Federal de Santa Catarina (UFSC). Professora adjunta da Universidade Federal de Santa Catarina (UFSC), no programa de Pós-Graduação e no Curso de Psicologia. Endereço postal: Departamento de Psicologia, sala 07, Bloco B, Centro de Filosofia e Ciências Humanas - CFH, Universidade Federal de Santa Catarina UFSC. Campus Reitor João David Ferreira Lima, s/n- Trindade, Florianópolis, SC - CEP: 88040-900. Contato: menezes.marina@ufsc.br https://orcid.org/0000-0002-8518-8684 


\section{Social network in palliative care: an integrative review of literature}

This work aims to analyze the characteristics of the functions of members of social networks configured around relatives of patients in palliative care. Articles from the past decade were selected from PsycINFO, Web of Science and Scopus. After considering specific descriptors and the study objective, 30 articles were selected. The results showed: a) predominantly qualitative research, b) ambivalent perceptions of caregivers in relation to care offered by institutional support and family networks, c) presence of feelings of exhaustion, gratification, anxiety and depression, during the care process. Further research on aboutpalliative care is necessary in Brazil and other Latin American countries.

Keywords: palliative care, family, social support, social networks, literature review.

\section{Redes sociales en los cuidados paliativos: una revisión integrativa de la literatura}

Este trabajo tuvo por objetivo analizar las características de las funciones de los miembros de las redes sociales configuradas alrededor de familiares de pacientes en cuidados paliativos. PsycINFO, Web of Science y Scopus, fueron las bases consultadas sobre trabajos publicados en la última década. Considerando descriptores específicos y el objetivo se seleccionaron 30 artículos. Los resultados constataron: a) predominio de investigaciones cualitativas, b) percepciones ambivalentes de cuidadores con relación al cuidado ofrecidos por el suporte institucional y por las redes familiares, c) presencia de sentimientos de agotamiento, gratificación, ansiedad y depresión, durante el proceso de cuidado. Se constató la necesidad de producción de investigaciones sobre cuidados paliativos, en Brasil y demás países de América Latina, relacionadas al objetivo de este estudio.

Palabras clave: cuidados paliativos, familia, apoyo social, redes sociales, revisión de literatura.

\section{Réseaux sociaux en soins palliatifs: une revue intégrative de la littérature}

Ce travail vise à analyser les caractéristiques des fonctions des membres des réseaux sociaux configurés autour des proches des patients en soins palliatifs. PsycINFO, Web of Science et Scopus, ont été les bases consultées. Compte tenu des descripteurs spécifiques et de l'objectif, 30 articles ont été sélectionnés. Les résultats ont montré: a) prédominance de la recherche qualitative, b) perceptions ambivalentes des soignants par rapport aux soins offerts par le soutien institutionnel et les réseaux familiaux, c) présence de sentiments d'épuisement, de gratification, d'anxiété et de dépression pendant le processus de soins. Il a été vérifié la nécessité de produire des connaissances dans le contexte des soins palliatifs au Brésil et dans d'autres pays d'Amérique latine était liée à l'objectif de ce travail.

Mots-clés: soins palliatifs, la famille soutien social, réseaux sociaux, revue de la littérature. 
De acordo com dados da Organização Mundial da Saúde (OMS), em 2008 ocorreram 36 milhóes de mortes no mundo por doenças crônicas, o que corresponde a um percentual de 63\% das mortes. Quatro anos depois, o número de mortes aumentou para 38 milhóes e até 2030 estima-se que esse número seja de aproximadamente 52 milhóes (World Health Organization - WHO, 2014). Em 2007, especificamente, na América Latina e no Caribe, as doenças crônicas representaram a principal causa de mortalidade, com 68\% das mortes. Dez anos depois, apesar da mortalidade por doenças crônicas não transmissíveis ter diminuído, nas Américas, elas são responsáveis por aproximadamente quatro em cada cinco mortes no ano (Organização Pan-Americana da Saúde, 2017; Pan American Health Organization, 2007). Nesse âmbito, a OMS pondera que mais 20 milhóes de pessoas necessitam de Cuidados Paliativos no fim da vida (Worldwide Palliative Care Alliance - WPCA, 2014).

A definição de Cuidados Paliativos de acordo com a Organização Mundial da Saúde (OMS), propõe que estes são cuidados promovidos por uma equipe multiprofissional, que visam proporcionar qualidade de vida para o paciente e seus familiares frente a uma doença limitadora à vida, por meio da prevenção de sintomas físicos, psicossociais ou espirituais, e alívio da dor e do sofrimento oriundos destes (WHO, 2002). Esses cuidados tem como âmago principal a identificação precoce dos sintomas e podem ser desenvolvidos durante todo o curso da doença, combinado a outros tratamentos de prolongamento da vida. Nesse sentido, os Cuidados Paliativos valorizam a morte como uma etapa da vida e buscam auxiliar o paciente a viver o mais ativamente possível até sua morte, e à família diante do processo de adoecimento até no suporte ao luto (WHO, 2002), de modo que a detecção das necessidades desta e a comunicação adequada são aspectos centrais nesse contexto (Silva \& Araújo, 2012). Cabe salientar que os Cuidados Paliativos podem ser 
entendidos em algumas situações, equivocadamente, como sinônimo de fim de vida, o que vai de encontro à definição da atenção integral proposta pela OMS. Por isso, neste artigo, foram selecionados estudos que haviam sido desenvolvidos no contexto dos Cuidados Paliativos, tendo eles sido realizados no momento de fim de vida ou durante outras fases da doença.

Os familiares são os principais responsáveis pelo cuidado ao paciente e, diante da vivência da doença crônica, precisam mobilizar diferentes recursos a fim de manejar as mudanças, a reorganização de papéis e o cuidado ao paciente. A família desempenha uma importante função no processo de cuidado e a imersão nesse contexto faz com que o adoecimento e a morte tragam modificaçóes na vida familiar, que podem ser sutis ou drásticas, as quais geram necessidades e sentimentos que variam desde o início da doença até o pós-morte (Kübler-Ross, 1981). De acordo com Rolland (1995), o adoecimento crônico e a morte são considerados eventos estressores dentro do ciclo de vida familiar. $\mathrm{O}$ modo como estes estressores atuam na família depende de condiçóes relativas à doença, como: o seu início, o curso, as fases, as consequências, o grau de incapacitação e da história da família em relação à doença, às perdas e à crise (Rolland, 1995). Diante disso, durante o adoecimento e fim de vida do paciente, este e seus familiares vivenciam o luto antecipatório, um processo dinâmico, que tem início frente à iminência da finitude, e é atravessado por um conjunto de perdas, pela possibilidade de resolução de conflitos, rituais de despedida e preparação para a morte (Franco, 2014; Overton \& Cottone, 2016). Frente a essas situaçóes de doença e morte, os familiares podem recorrer ao auxílio das crenças espirituais e religiosas, que oferecem sentido e conforto para estes eventos (Bousso, Poles, Serafim \& Miranda, 2011), dentre outras estratégias.

$\mathrm{Na}$ proposta dos cuidados integrais, os hospices sáo espaços onde se propõe atenção integral ao paciente e à família, ofertada por uma equipe de saúde e por voluntários. Esses locais são espaços centrais nos Cuidados Paliativos, especialmente em países em que eles já se encontram desenvolvidos (WPCA, 2014). Os hospices, enquanto espaço de 
saúde, assim como a equipe, a unidade, os serviços e os profissionais que atuam promovendo os Cuidados Paliativos, podem ser considerados como exemplos de uma rede de suporte social. O suporte social, ou redes formais, representam instituições e organizaçóes que buscam oferecer suporte, com medidas de prevenção e promoção de saúde, a fim de minimizar situaçóes de estresse e proporcionar maior bem-estar (Ornelas, 2008). A presença do suporte social modifica o contexto situacional, de modo que essas redes de suporte podem contribuir para o bem estar individual e para os sentimentos de autoestima e adaptação (Ornelas, 1997). Ainda, as redes compostas pelos profissionais podem desempenhar uma função relevante na vivência do luto antecipatório, ao validar os sentimentos vivenciados por pacientes e familiares, e acolhê-los (Braz \& Franco, 2017).

Além do suporte social, observam-se as redes sociais configuradas em torno de um evento vital - neste caso, o adoecimento crônico e fim de vida nos Cuidados Paliativos- que podem funcionar como facilitadoras no processo de cuidado, uma vez que oferecem o senso de compartilhamento e promovem a diminuição do estresse. Essas redes podem ser consideradas significativas, na medida em que elas se configuram a partir das histórias de vínculos afetivos compartilhados. São definidas por Sluzki (1997) como o conjunto de todas aquelas pessoas que o indivíduo considera importantes e/ou significativas no contexto de seu universo relacional, e que oferecem auxílio em momentos de crise, tais como: família, amigos, vizinhos, colegas de trabalho e pessoas da comunidade, grupos religiosos. As redes podem ser consideradas conforme suas características estruturais, pelas funçôes dos vínculos e pelos atributos dos mesmos, de acordo com a história relacional dos envolvidos. De acordo com o autor acima mencionado, é possível observar seis tipos de funçóes da rede social significativa: 1. Companhia social; 2. Apoio emocional; 3. Guia cognitivo e conselhos; 4. Regulação social; 5. Ajuda material e de serviços; e 6. Acesso a novos contatos (Sluzki, 1997).

A companhia social é quando os membros desempenham a função de "estar com", estando próximos, realizando atividades ou não. 
As redes podem desempenhar uma função compreensiva, o senso de compartilhamento, apoio e empatia, o que caracteriza a funçáo do apoio emocional. Quando os membros das redes oferecem um protótipo de papel a ser seguido e compartilham informaçóes pessoais ou sociais, elas desempenham a função de guia cognitivo e de conselhos, ao passo que ao auxiliar na resolução de conflitos, em situaçóes que não correspondem à expectativa coletiva, a rede exerce sua funçáo de regulaçấo ou controle social. Nos momentos em que as redes proporcionam para o indivíduo acesso a novas pessoas e vínculos, exercem a função de acesso a novos contatos. Já a ajuda material e de serviços é desempenhada quando há o acesso a conhecimentos específicos, serviços de saúde ou ajuda física (Sluzki, 1997).

No que tange às produçóes científicas sobre o tema, cabe mencionar que diferentes termos, tais como "apoio/suporte social", "redes formais", "redes sociais" são utilizados como sinônimo do mesmo fenômeno, embora não sejam conceituadas na sua especificidade. Tendo isso em vista, neste estudo, foram respeitadas as definiçóes empregadas pelos autores em cada artigo, mas o processo de compreensão e categorização levou em consideração os conceitos aqui explicitados.

Ao considerar o crescente número de pessoas com doenças crônicas e a sobrecarga que os cuidados geram para os cuidadores familiares, destaca-se a relevância de compreender como as produçôes científicas referem às funçóes dos membros das redes sociais significativas de familiares de pacientes em Cuidados Paliativos. Isso por que, os achados da revisão podem embasar pesquisas empíricas que considerem a importância das pessoas das redes como corresponsáveis pelo cuidado dos pacientes em Cuidados Paliativos e seus familiares. Por sua vez, considera-se que essas redes, de certo modo, são invisibilizadas nas práticas de saúde, seja na sua potencialidade de corresponsabilidade pelo cuidado, como também nas consequências da vivencia de luto/perda de um ente querido. Assim, o presente artigo de revisão integrativa de literatura objetivou analisar as características das funçôes dos membros das redes sociais configuradas em torno de familiares de pacientes em Cuidados Paliativos. 
Redes sociais nos cuidados paliativos: uma revisão integrativa da literatura / Reis et al.

\section{Método}

Este estudo se caracteriza como uma revisão integrativa da literatura, que propóe a sintetização e revisão crítica dos materiais já publicados e que sáo representativos de determinada temática, com intuito de gerar novas perspectivas sobre o assunto (Torraco, 2005). A fim de responder a seguinte pergunta: "Quais as características das funções dos membros das redes sociais dos familiares de pacientes em Cuidados Paliativos?", realizou-se a busca de artigos empíricos nas bases dados Web of Science, PsycINFO e Scopus, no período referente a janeiro de 2007 a março de 2018.

Com a intenção de alcançar um maior número de artigos, utilizou-se o VPN (Virtual Private Network) da Universidade a qual as autoras do presente estudo estão vinculadas. Para a efetivação da busca, foram utilizados os descritores disponíveis na plataforma DeCS (Descritores em Ciência da saúde), conforme sua correspondência em inglês: "cuidados paliativos"/"palliative care", "suporte social"/"social support", "redes sociais"/"social networks", combinados por meio dos operadores booleanos $O R$ e $A N D$. Os documentos selecionados foram artigos, com texto completo disponível, escritos nas línguas inglesa, espanhola ou portuguesa, conforme os critérios de inclusão previamente estabelecidos: a) ser um artigo empírico, b) referir-se ao contexto dos Cuidados Paliativos segundo a definição adotada pelas autoras e descrito na introdução, c) cujos participantes fossem familiares cuidadores e d) descrevessem aspectos de suas redes sociais configuradas, durante o cuidado do paciente ou período de luto.

Dos 1.476 documentos encontrados nas bases de dados (aplicado os filtros de cada base referente aos anos, tipo de documento, língua), 87 artigos foram selecionados após a leitura dos seus títulos e resumos. Destes, seis se encontravam em mais de uma base de dados, tendo sido excluídos por motivo de duplicação. Após a leitura dos textos completos, 51 documentos foram excluídos, pois: a) os participantes eram os profissionais da saúde (6 artigos); b) os participantes eram os pacientes (14 artigos); c) o contexto dos Cuidados Paliativos não estava definido 
de maneira clara, ou seja, não era possível identificar se os familiares estavam recebendo tais cuidados (11 artigos); e d) não estabelecia a relação entre a rede social dos familiares e o contexto dos Cuidados Paliativos (20 artigos). Diante disso, 30 artigos corresponderam aos critérios para compor a presente revisão. A seleção dos estudos contou com a participação de duas juízas com experiência em pesquisas na área saúde e redes sociais significativas, com vistas à melhor inclusão e/ou exclusão de artigos relacionados ao objetivo do trabalho. $\mathrm{O}$ fluxo de seleção dos estudos pode ser visualizado na Figura 1.

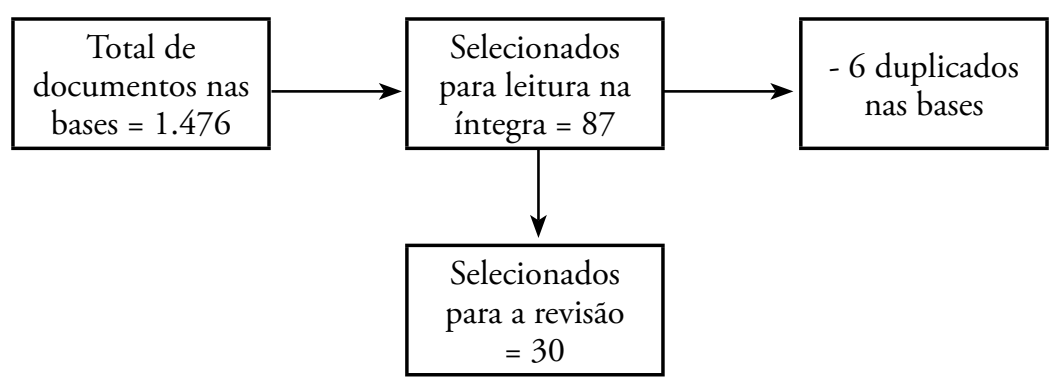

Figura 1. Fluxo do processo de seleção dos estudos para revisão integrativa

Os dados foram organizados em categorias e subcategorias, conforme análise de conteúdo temática (Olabuénaga, 2009), que visa uma leitura crítica e aprofundada do material selecionado. Após leitura exaustiva do material e a extração dos seus conteúdos referentes à pergunta de pesquisa, os temas foram organizados de acordo com as principais funções desempenhadas pelos membros das redes, pelos profissionais da saúde e os temas recorrentes que se referiam ao processo de cuidado. Assim, os dados foram organizados em três categorias e respectivas subcategorias e elementos de análise, as quais são apresentadas no item a seguir. 


\section{Resultados e discussáo}

Quanto às características dos estudos, dos 30 artigos selecionados para esta revisão, 19 são estudos de abordagem qualitativa, seis quantitativa e cinco são de abordagem mista. As técnicas e instrumentos de coleta de dados variaram entre: questionários, entrevistas semiestruturadas, grupos focais, entrevistas em profundidade, escalas, inventários e observação, sendo que doze dessas pesquisas utilizaram mais de uma técnica de coleta de dados.

Todos os artigos estâo escritos na língua inglesa e o país onde há o maior número de estudos desenvolvidos é o Canadá $(\mathrm{n}=7)$, seguido da Austrália $(n=5)$ e em igual número $(n=3)$ estão Suécia, Inglaterra, Alemanha e Uganda. O alto número de publicaçôes, especialmente na Austrália e Canadá, pode ser reflexo da alta expectativa de vida nestes países (WHO, 2016) e, consequentemente, pela busca do desenvolvimento de um sistema de cuidados de longo prazo que garanta o envelhecimento em lugares adequados, que permita os vínculos com a comunidade e com as redes sociais, tal como preza a OMS em relatório divulgado (OMS, 2015). Em menor número de publicaçôes estão: Suíça (1), Estados Unidos (2), Coreia do Sul (1), China (1), Nova Zelândia (1), África do Sul (1), Kenya (1) e Malawi (1). Cabe ressaltar que um mesmo estudo foi desenvolvido na Uganda, Kenya e Malawi e outro na Uganda e África do Sul. A crescente publicação destes países da África pode ter relaçáo com um aumento de 9,4 anos na expectativa de vida da populaçáo africana, reflexo do maior acesso aos antirretrovirais para o tratamento do HIV/Aids, o controle da malária e aumento dos índices de sobrevivência infantil (WHO, 2016). Nenhum estudo oriundo do Brasil, nem da América Latina foi encontrado dentro dos critérios de seleçáo previamente estabelecidos, o que revela uma lacuna na produçáo de pesquisas nesta regiáo que trate sobre as características das funçôes das redes sociais e os Cuidados Paliativos.

Os artigos foram publicados nos anos de $2007(\mathrm{n}=1), 2009(\mathrm{n}=$ 5), $2010(\mathrm{n}=3), 2011(\mathrm{n}=3), 2012(\mathrm{n}=3), 2013(\mathrm{n}=3), 2014(\mathrm{n}=2)$, $2015(\mathrm{n}=2), 2016(\mathrm{n}=2), 2017(\mathrm{n}=4)$, até março $2018(\mathrm{n}=2)$, o que 
demonstra uma distribuição regular das publicações, havendo um indicativo crescente no ano de 2017, que não pôde ser verificado em 2018 devido à limitação de tempo da presente revisão. Destaca-se que dos quatro artigos publicados em 2017, dois são da Austrália, sendo que os do ano de 2018 foram do Canada e Nova Zelândia.

Os principais resultados dos estudos selecionados foram organizados em três categorias centrais (figuras 2, 3 e 4): 1) Percepção do Suporte Social dos familiares cuidadores nos Cuidados Paliativos, que conta com as subcategorias: Funçôes da Rede de Suporte Social (1.1) e Sentimentos e percepções em relação aos profissionais de saúde (1.2); 2) Redes Sociais Significativas nos Cuidados Paliativos, subdividida em Família (2.1), Amigos (2.2) e Comunidade (2.3); 3) Cuidador no contexto de Cuidados Paliativos, com as subcategorias: Cuidado na fase final de vida (3.1) e Sentimentos do cuidador relativos ao trabalho de cuidar (3.2). Os elementos de análise, especificados nas figuras situadas em cada categoria, balizam a discussão dos resultados. Os artigos selecionados para composição desta revisão são apresentados na Tabela 1 .

\section{Tabela 1}

Artigos selecionados para a Revisão de literatura

\begin{tabular}{|c|c|c|c|c|c|}
\hline Título & Ano & Autores & Objetivo & $\begin{array}{l}\text { Abor- } \\
\text { dagem }\end{array}$ & $\begin{array}{l}\text { Cate- } \\
\text { goria }(s)\end{array}$ \\
\hline $\begin{array}{l}\text { Volunteer navigation } \\
\text { partnerships: Piloting a } \\
\text { compassionate community } \\
\text { approach to early palliative } \\
\text { care }\end{array}$ & 2018 & $\begin{array}{l}\text { Pesut } \\
\text { et al. }\end{array}$ & $\begin{array}{l}\text { Reportar os achados do } \\
\text { projeto N-CARE. }\end{array}$ & Mista & 1 \\
\hline $\begin{array}{l}\text { What is the role of } \\
\text { community at the end of } \\
\text { life for people dying in } \\
\text { advanced age? A qualitative } \\
\text { study with bereaved family } \\
\text { carers }\end{array}$ & 2018 & $\begin{array}{l}\text { Gott } \\
\text { et al. }\end{array}$ & $\begin{array}{l}\text { Explorar o papel da comuni- } \\
\text { dade no fim de vida de pessoas } \\
\text { morrendo com idade avança- } \\
\text { da, na perspectiva de familia- } \\
\text { res cuidadores enlutados. }\end{array}$ & $\begin{array}{l}\text { Quali- } \\
\text { tativa }\end{array}$ & 3 \\
\hline $\begin{array}{l}\text { Building Community } \\
\text { Capacity in Bereavement } \\
\text { Support: Lessons Learnt } \\
\text { From Bereaved Caregivers }\end{array}$ & 2017 & $\begin{array}{l}\text { Breen } \\
\text { et al. }\end{array}$ & $\begin{array}{l}\text { Explorar os conselhos que as } \\
\text { pessoas enlutadas têm para ou- } \\
\text { tras em situaçáo semelhante. }\end{array}$ & $\begin{array}{l}\text { Quali- } \\
\text { tativa }\end{array}$ & 2 e 3 \\
\hline
\end{tabular}


Redes sociais nos cuidados paliativos: uma revisão integrativa da literatura / Reis et al.

\begin{tabular}{|c|c|c|c|c|c|}
\hline Título & Ano & Autores & Objetivo & $\begin{array}{l}\text { Abor- } \\
\text { dagem }\end{array}$ & $\begin{array}{c}\text { Cate- } \\
\text { goria (s) }\end{array}$ \\
\hline $\begin{array}{l}\text { Development of a } \\
\text { measure (ICECAP-Close } \\
\text { Person Measure) through } \\
\text { qualitative methods to } \\
\text { capture thebenefits of end- } \\
\text { of-life care to those close } \\
\text { to the dying for use in } \\
\text { economic evaluation }\end{array}$ & 2017 & $\begin{array}{l}\text { Canaway, } \\
\text { Al-Janabi, } \\
\text { Kinghorn, } \\
\text { Bailey e } \\
\text { Coast }\end{array}$ & $\begin{array}{l}\text { Desenvolver uma medida ade- } \\
\text { quada para uso em avaliaçáo } \\
\text { econômica que capte os bene- } \\
\text { fícios dos cuidados de final de } \\
\text { vida para aqueles próximos às } \\
\text { pessoas em fim de vida. }\end{array}$ & $\begin{array}{l}\text { Quali- } \\
\text { tativa }\end{array}$ & 1 e 3 \\
\hline $\begin{array}{l}\text { Maintaining family life } \\
\text { balance while facing a } \\
\text { child's imminent death-A } \\
\text { mixed methods study }\end{array}$ & 2017 & $\begin{array}{l}\text { Eskola, } \\
\text { Berg- } \\
\text { straesser, } \\
\text { Zimmer- } \\
\text { mann e } \\
\text { Cignacco }\end{array}$ & $\begin{array}{l}\text { Compreender as experiências } \\
\text { dos pais e necessidades duran- } \\
\text { te o cuidado de fim de vida da } \\
\text { criança em casa e identificar } \\
\text { os fatores que influenciaram } \\
\text { sua provisão. }\end{array}$ & Mista & 1,2 e 3 \\
\hline $\begin{array}{l}\text { Bereavement support for } \\
\text { family caregivers the gap } \\
\text { between guidelines and } \\
\text { practice in palliative care }\end{array}$ & 2017 & $\begin{array}{l}\text { Aoun, } \\
\text { Rumbold, } \\
\text { Howting, } \\
\text { Bolleter e } \\
\text { Breen }\end{array}$ & $\begin{array}{l}\text { Identificar padróes de apoio } \\
\text { ao luto em serviços de Cui- } \\
\text { dados Paliativos baseados na } \\
\text { experiência de pessoas enluta- } \\
\text { das de uma pesquisa de base } \\
\text { populacional e em relação a } \\
\text { diretrizes de prática clínica. }\end{array}$ & $\begin{array}{l}\text { Quanti- } \\
\text { tativa }\end{array}$ & 1,2 e 3 \\
\hline $\begin{array}{l}\text { Examining the Experiences } \\
\text { of Fathers of Children with } \\
\text { a Life-Limiting Illness }\end{array}$ & 2016 & $\begin{array}{c}\text { Nicholas } \\
\text { et al. }\end{array}$ & $\begin{array}{l}\text { Conhecer as experiências pa- } \\
\text { ternas e as necessidades de } \\
\text { apoio associadas à doença li- } \\
\text { mitadora da vida na infância. }\end{array}$ & $\begin{array}{l}\text { Quali- } \\
\text { tativa }\end{array}$ & 1,2 e 3 \\
\hline $\begin{array}{l}\text { Lived experiences of } \\
\text { parents caring for a } \\
\text { child with a life-limiting } \\
\text { condition in Australia: A } \\
\text { qualitative study }\end{array}$ & 2016 & Collins et al. & $\begin{array}{l}\text { Explorar as experiências } \\
\text { prevalentes vividas pelos pais } \\
\text { no cuidado de uma criança } \\
\text { com uma condição limitadora } \\
\text { da vida na Austrália. }\end{array}$ & $\begin{array}{l}\text { Quali- } \\
\text { tativa }\end{array}$ & 1,2 e 3 \\
\hline $\begin{array}{l}\text { Identifying socio- } \\
\text { environmental factors that } \\
\text { facilitate resilience among } \\
\text { canadian palliative family } \\
\text { caregivers a qualitative case }\end{array}$ & 2015 & $\begin{array}{l}\text { Giesbrecht, } \\
\text { Wolse, } \\
\text { Crooks e } \\
\text { Stajduhar }\end{array}$ & $\begin{array}{l}\text { Identificar fatores socioam- } \\
\text { bientais que contribuem para } \\
\text { a resiliência do familiar cuida- } \\
\text { dor do paciente paliativo no } \\
\text { contexto da assistência domi- } \\
\text { ciliar canadense. }\end{array}$ & $\begin{array}{l}\text { Quali- } \\
\text { tativa }\end{array}$ & 1 e 2 \\
\hline $\begin{array}{l}\text { Risk Factors for } \\
\text { Anticipatory Grief in } \\
\text { Family members of } \\
\text { terminally ill veterans } \\
\text { receiving palliative care } \\
\text { services }\end{array}$ & 2015 & Burke et al. & $\begin{array}{l}\text { Avaliar as experiências de pré- } \\
\text {-perda do luto de familiares } \\
\text { que estáo antecipando a perda } \\
\text { de um veterano como resulta- } \\
\text { do de uma doença terminal e } \\
\text { avaliar fatores de risco demo- } \\
\text { gráficos, relacionais, emocio- } \\
\text { nais e existenciais para o luto } \\
\text { antecipatório. }\end{array}$ & $\begin{array}{l}\text { Quanti- } \\
\text { tativa }\end{array}$ & 3 \\
\hline
\end{tabular}




\begin{tabular}{|c|c|c|c|c|c|}
\hline Título & Ano & Autores & Objetivo & $\begin{array}{l}\text { Abor- } \\
\text { dagem }\end{array}$ & $\begin{array}{l}\text { Cate- } \\
\text { goria }(s)\end{array}$ \\
\hline $\begin{array}{l}\text { Psychological distress and } \\
\text { quality of life of palliative } \\
\text { cancerpatients and their } \\
\text { caring relatives during } \\
\text { home care }\end{array}$ & 2014 & $\begin{array}{l}\text { Götze, } \\
\text { Brähler, } \\
\text { Gansera, } \\
\text { Polze e } \\
\text { Köhler }\end{array}$ & $\begin{array}{l}\text { Examinar o nível de estresse } \\
\text { psicológico e qualidade de } \\
\text { vida em pacientes com câncer } \\
\text { em cuidados paliativos e seus } \\
\text { familiares cuidadores; investi- } \\
\text { gar o impacto dos fatores so- } \\
\text { ciodemográficos relacionados } \\
\text { ao cuidado no estresse psicoló- } \\
\text { gico em pacientes em cuidados } \\
\text { paliativos e seus familiares. }\end{array}$ & $\begin{array}{l}\text { Quanti- } \\
\text { tativa }\end{array}$ & 1,2 e 3 \\
\hline $\begin{array}{l}\text { Social capital in a lower } \\
\text { socioeconomic palliative } \\
\text { care population: a } \\
\text { qualitative investigation of } \\
\text { individual, community and } \\
\text { civic networks and relations }\end{array}$ & 2014 & $\begin{array}{l}\text { Lewis, } \\
\text { DiGiacomo, } \\
\text { Currow e } \\
\text { Davidson }\end{array}$ & $\begin{array}{l}\text { Explorar a natureza do capital } \\
\text { social em um grupo socioeco- } \\
\text { nomicamente desfavorecido } \\
\text { de pacientes em cuidados pa- } \\
\text { liativos e cuidadores }\end{array}$ & $\begin{array}{l}\text { Quali- } \\
\text { tativa }\end{array}$ & 2 \\
\hline $\begin{array}{l}\text { Community Systems } \\
\text { Strengthening for HIV } \\
\text { Care: Experiences From } \\
\text { Uganda }\end{array}$ & 2013 & Mburu et al. & $\begin{array}{l}\text { Identificar os elementos do } \\
\text { sistema comunitário que faci- } \\
\text { litam a provisão de cuidado. }\end{array}$ & $\begin{array}{l}\text { Quali- } \\
\text { tativa }\end{array}$ & 2 e 3 \\
\hline $\begin{array}{l}\text { Finding the right kind of } \\
\text { support: A study of carers } \\
\text { of those with a primary } \\
\text { malignant brain tumour }\end{array}$ & 2013 & $\begin{array}{l}\text { Arber, } \\
\text { Hutson, } \\
\text { Vries e } \\
\text { Guerrero }\end{array}$ & $\begin{array}{l}\text { Examinar as necessidades de } \\
\text { suporte dos cuidadores de } \\
\text { pacientes com tumor cerebral } \\
\text { maligno primário. }\end{array}$ & $\begin{array}{l}\text { Quali- } \\
\text { tativa }\end{array}$ & 1,2 e 3 \\
\hline $\begin{array}{l}\text { Determinants of the Effect } \\
\text { of Existential Behavioral } \\
\text { Therapy for Bereaved } \\
\text { Partners: A Qualitative } \\
\text { Study }\end{array}$ & 2013 & $\begin{array}{l}\text { Kögler, } \\
\text { Brandl, } \\
\text { Brand- } \\
\text { sta" tter, } \\
\text { Borasio e } \\
\text { Fegg }\end{array}$ & $\begin{array}{l}\text { Compreender o que os partici- } \\
\text { pantes perceberam como úteis } \\
\text { para lidar com sua perda du- } \\
\text { rante o primeiro ano do luto. }\end{array}$ & $\begin{array}{l}\text { Quali- } \\
\text { tativa }\end{array}$ & 2 \\
\hline $\begin{array}{l}\text { Religious Beliefs and } \\
\text { Practices in End-Stage } \\
\text { Renal Disease: Implications } \\
\text { for Clinicians }\end{array}$ & 2012 & $\begin{array}{l}\text { Elliott, } \\
\text { Gessert, } \\
\text { Larson e } \\
\text { Russ }\end{array}$ & $\begin{array}{l}\text { Investigar como pacientes em } \\
\text { estágio final da doença renal e } \\
\text { suas famílias tomam decisôes e } \\
\text { lidam com suas circunstâncias } \\
\text { e tratamento de diálise. }\end{array}$ & $\begin{array}{l}\text { Quali- } \\
\text { tativa }\end{array}$ & 2 \\
\hline $\begin{array}{l}\text { Supporting hospice } \\
\text { volunteers and caregivers } \\
\text { through community-based } \\
\text { participatory research }\end{array}$ & 2012 & $\begin{array}{l}\text { MacLeod, } \\
\text { Skinner e } \\
\text { Low }\end{array}$ & $\begin{array}{l}\text { Envolver as partes interessa- } \\
\text { das em cuidados paliativos } \\
\text { na identificação, priorização e } \\
\text { implementação de interven- } \\
\text { çôes de apoio social para cui- } \\
\text { dadores. }\end{array}$ & $\begin{array}{l}\text { Quali- } \\
\text { tativa }\end{array}$ & 1,2 e 3 \\
\hline
\end{tabular}


Redes sociais nos cuidados paliativos: uma revisão integrativa da literatura / Reis et al.

\begin{tabular}{|c|c|c|c|c|c|}
\hline Título & Ano & Autores & Objetivo & $\begin{array}{l}\text { Abor- } \\
\text { dagem }\end{array}$ & $\begin{array}{l}\text { Cate- } \\
\text { goria }(s)\end{array}$ \\
\hline $\begin{array}{l}\text { "That must be so hard" } \\
\text { examining the impact } \\
\text { of childrens palliative } \\
\text { care services on the } \\
\text { psychological well being of } \\
\text { parents }\end{array}$ & 2012 & $\begin{array}{l}\text { Gupta e } \\
\text { Prescott }\end{array}$ & $\begin{array}{l}\text { Determinar o impacto dos } \\
\text { serviços de cuidados paliativos } \\
\text { para crianças recém-encami- } \\
\text { nhadas com condiçóes não- } \\
\text {-malignas, limitadoras e com } \\
\text { risco de vida e suas famílias, } \\
\text { em termos de estresse dos pais } \\
\text { e bem-estar psicológico. }\end{array}$ & $\begin{array}{l}\text { Quanti- } \\
\text { tativa }\end{array}$ & 1 \\
\hline $\begin{array}{l}\text { Palliative care making a } \\
\text { difference in rural uganda, } \\
\text { kenya and malawi: three } \\
\text { rapid evaluation field } \\
\text { studies }\end{array}$ & 2011 & $\begin{array}{l}\text { Grant, } \\
\text { Brown, } \\
\text { Leng, } \\
\text { Bettega e } \\
\text { Murray }\end{array}$ & $\begin{array}{l}\text { Descrever as perspectivas do } \\
\text { paciente, da família e da co- } \\
\text { munidade local sobre três } \\
\text { projetos de cuidados paliativos } \\
\text { baseados na comunidade, cada } \\
\text { um em um país com alta pre- } \\
\text { valência de HIV. }\end{array}$ & $\begin{array}{l}\text { Quali- } \\
\text { tativa }\end{array}$ & 1,2 e 3 \\
\hline $\begin{array}{l}\text { Canada's Compassionate } \\
\text { Care Benefit: Is it an } \\
\text { adequate public health } \\
\text { response to adressing the } \\
\text { issue of caregiver burden in } \\
\text { end-of-life care? }\end{array}$ & 2011 & $\begin{array}{l}\text { Williams } \\
\text { et al. }\end{array}$ & $\begin{array}{l}\text { Examinar como o Canada's } \\
\text { Compassionate Care Benefit } \\
\text { opera como resposta de saúde } \\
\text { pública para manter cuidado- } \\
\text { res informais que prestam cui- } \\
\text { dados de fim de vida e se abor- } \\
\text { dam adequadamente aspectos } \\
\text { da sobrecarga do cuidador do } \\
\text { modelo de promoçáo da saúde } \\
\text { da população. }\end{array}$ & $\begin{array}{l}\text { Quali- } \\
\text { tativa }\end{array}$ & 1,2 e 3 \\
\hline $\begin{array}{l}\text { Quality of life and mental } \\
\text { health in family caregivers } \\
\text { of patients with terminal } \\
\text { cancer }\end{array}$ & 2011 & $\begin{array}{l}\text { Song } \\
\text { et al. }\end{array}$ & $\begin{array}{l}\text { Descrever a qualidade de vida } \\
\text { e a saúde mental dos cuida- } \\
\text { dores familiares na Coreia em } \\
\text { comparaçáo com os da popu- } \\
\text { laçáo em geral e investigar os } \\
\text { fatores associados. }\end{array}$ & $\begin{array}{l}\text { Quanti- } \\
\text { tativa }\end{array}$ & 2 \\
\hline $\begin{array}{l}\text { The significance of fatigue } \\
\text { in relatives of palliative } \\
\text { patients }\end{array}$ & 2010 & Carlsson & $\begin{array}{l}\text { Explorar o significado da fa- } \\
\text { tiga em parentes de pacientes } \\
\text { em cuidados paliativos. }\end{array}$ & $\begin{array}{l}\text { Quali- } \\
\text { tativa }\end{array}$ & 1,2 e 3 \\
\hline $\begin{array}{l}\text { The transition experience } \\
\text { of rural older persons } \\
\text { with advanced cancer and } \\
\text { their families: A grounded } \\
\text { theory study }\end{array}$ & 2010 & $\begin{array}{l}\text { Duggleby } \\
\text { et al. }\end{array}$ & $\begin{array}{l}\text { Descrever as experiências de } \\
\text { transiçôes significativas de pes- } \\
\text { soas idosas com câncer avança- } \\
\text { do que vivem em áreas rurais e } \\
\text { suas famílias. }\end{array}$ & $\begin{array}{l}\text { Quali- } \\
\text { tativa }\end{array}$ & 1,2 e 3 \\
\hline $\begin{array}{l}\text { Post-mortal bereavement } \\
\text { of family caregivers in } \\
\text { Germany }\end{array}$ & 2010 & Wiese et al. & $\begin{array}{l}\text { Avaliar o luto pós morte dos } \\
\text { familiares cuidadores. }\end{array}$ & Mista & 1 e 3 \\
\hline
\end{tabular}




\begin{tabular}{|c|c|c|c|c|c|}
\hline Título & Ano & Autores & Objetivo & $\begin{array}{l}\text { Abor- } \\
\text { dagem }\end{array}$ & $\begin{array}{l}\text { Cate- } \\
\text { goria }(s)\end{array}$ \\
\hline $\begin{array}{l}\text { Family and friends provide } \\
\text { most social support for the } \\
\text { bereaved }\end{array}$ & 2009 & $\begin{array}{l}\text { Benkel, } \\
\text { Wijk e } \\
\text { Molander } \\
\text { (a) }\end{array}$ & $\begin{array}{l}\text { Explorar o suporte social espe- } \\
\text { rado e recebido por um paren- } \\
\text { te próximo ou amigo durante } \\
\text { o primeiro ano após a morte } \\
\text { do ente querido que esteve } \\
\text { internado em uma unidade de } \\
\text { Cuidados Paliativos na Suécia. }\end{array}$ & Mista & 1,2 e 3 \\
\hline $\begin{array}{l}\text { Managing Grief and } \\
\text { Relationship Roles } \\
\text { Influence Which Forms } \\
\text { of Social Support the } \\
\text { Bereaved Needs }\end{array}$ & 2009 & $\begin{array}{l}\text { Benkel, } \\
\text { Wijk e } \\
\text { Molander } \\
\text { (b) }\end{array}$ & $\begin{array}{l}\text { É possível detectar que } \\
\text { influência o processo de luto } \\
\text { exerce sobre o indivíduo para } \\
\text { reconhecer as pessoas que } \\
\text { precisam de apoio especial } \\
\text { da equipe profissional da } \\
\text { equipe paliativa e planejar } \\
\text { para que tipo de apoio social é } \\
\text { necessário? }\end{array}$ & Mista & 1,2 e 3 \\
\hline $\begin{array}{l}\text { The meaning of being in } \\
\text { transition to end-of-life } \\
\text { care for female partners of } \\
\text { spouses with cancer }\end{array}$ & 2009 & Sutherland & $\begin{array}{l}\text { Explorar o significado de estar } \\
\text { em transiçáo para os cuidados } \\
\text { de final de vida entre mulhe- } \\
\text { res parceiras de cônjuges com } \\
\text { câncer. }\end{array}$ & $\begin{array}{l}\text { Quali- } \\
\text { tativa }\end{array}$ & 2 e 3 \\
\hline $\begin{array}{l}\text { The supportive and } \\
\text { palliative care needs of } \\
\text { Australian families of } \\
\text { children who die from } \\
\text { cancer }\end{array}$ & 2009 & $\begin{array}{l}\text { Monterosso, } \\
\text { Kristjanson } \\
\text { e Phillips }\end{array}$ & $\begin{array}{l}\text { Identificar as percepçóes de } \\
\text { pais de crianças que morreram } \\
\text { de câncer em relaçáo aos cui- } \\
\text { dados paliativos e de suporte } \\
\text { recebidos em um hospital e na } \\
\text { comunidade. }\end{array}$ & $\begin{array}{l}\text { Quanti- } \\
\text { tativa }\end{array}$ & 2 e 3 \\
\hline $\begin{array}{l}\text { Meeting information needs } \\
\text { of patients with incurable } \\
\text { progressive disease and } \\
\text { their families in South } \\
\text { Africa and Uganda: } \\
\text { multicentre qualitative } \\
\text { study }\end{array}$ & 2009 & Selman et al. & $\begin{array}{l}\text { Explorar as necessidades de } \\
\text { informaçáo de pacientes com } \\
\text { doença progressiva e limitan- } \\
\text { te da vida e seus cuidadores } \\
\text { familiares na África do Sul e } \\
\text { Uganda e informar a prática e } \\
\text { a política clínica neste campo } \\
\text { emergente. }\end{array}$ & $\begin{array}{l}\text { Quali- } \\
\text { tativa }\end{array}$ & 1 e 2 \\
\hline $\begin{array}{l}\text { The experiences of Chinese } \\
\text { family members of } \\
\text { terminally ill patients - a } \\
\text { qualitative study }\end{array}$ & 2007 & $\begin{array}{l}\text { Wong e } \\
\text { Chan }\end{array}$ & $\begin{array}{l}\text { Descrever e compreender as } \\
\text { experiências de familiares chi- } \\
\text { neses de pacientes com doença } \\
\text { terminal durante o processo de } \\
\text { final de vida em uma unidade } \\
\text { de Cuidados Paliativos. }\end{array}$ & $\begin{array}{l}\text { Quali- } \\
\text { tativa }\end{array}$ & 1 e 3 \\
\hline
\end{tabular}




\section{Percepçáo do Suporte Social dos familiares cuidadores nos}

\section{Cuidados Paliativos}

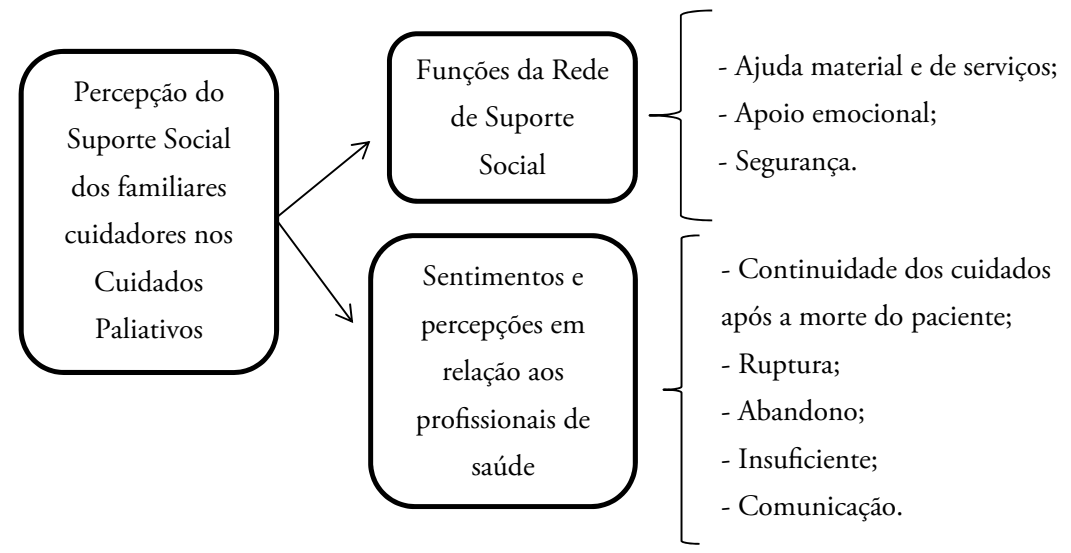

Figura 2. Principais resultados dos estudos: categoria 1, subcategorias e elementos de análise.

O Suporte Social nos Cuidados Paliativos, neste trabalho, é representado pelas açóes de auxílio e apoio dispensados pelos profissionais aos familiares, a fim de facilitar a vivência da situação de crise (Ornelas, 2008). A equipe de saúde tem um papel central nesse processo, uma vez que deve buscar oferecer apoio e orientação aos familiares, por meio de uma comunicação cuidadosa e centrada no vínculo (Gomes \& Othero, 2016). Nesse sentido, os profissionais de saúde tem papel decisivo nos Cuidados Paliativos, no enfrentamento dos processos de doença, morte e luto, uma vez que podem ser fonte de segurança ao escutar, acolher e validar os sentimentos dos familiares, podendo funcionar como um fator de proteção ao luto complicado (Braz \& Franco, 2017). Assim, em continuação o são destacadas as características que se referem às funçóes desempenhadas pelos profissionais da saúde no contexto dos Cuidados Paliativos, bem como os sentimentos e percepçóes dos familiares cuidadores em relação ao Suporte Social. 


\subsection{Funçöes da Rede de Suporte Social}

A Rede de Suporte Social, em quanto sua função, pode oferecer ajuda material e de serviços (1.1.1), o que foi observado nos estudos em que os familiares referiram auxílio dos profissionais de saúde no cuidado ao paciente, o que, por sua vez, permitiu a sensaçáo de normalidade na vida dos cuidadores (Canaway, Al-Janabi, Kinghorn, Bailey \& Coast, 2017). A ajuda foi oferecida diante dos arranjos funerários, bem como o aconselhamento legal e financeiro, especialmente no que tange aos assuntos e responsabilidades que eram do paciente e passaram a ser de encargo dos familiares, como cita o estudo de Benkel, Wijk e Molander (2009a). Quarenta por cento dos participantes relataram ter recebido tal suporte dos profissionais, o que contrariou suas expectativas, pois não esperavam receber o auxílio prático da equipe. Destaca-se que a assistência para o arranjo funerário, assim como o momento do funeral figuram como importantes elementos para o processo de luto (Benkel et al., 2009a).

O auxílio na divisão de tarefas relativas ao cuidado por parte dos enfermeiros domiciliares, a orientação médica e apoio dispendido foram apontados como fatores que favoreceram o desenvolvimento da resiliência dos cuidadores (Giesbrecht, Wolse, Crooks \& Stajduhar, 2015). Resultados do estudo com pais de crianças com doenças limitadoras e com risco de vida (Gupta \& Prescott, 2012) sugeriram que os serviços de Cuidados Paliativos podem ter auxiliado a evitar um aumento significativo dos níveis de estresse, uma vez que os cuidadores receberam apoio dos profissionais de enfermagem comunitária de crianças, da psicologia clínica, dos trabalhadores de Cuidados Paliativos e de profissionais especializados em luto e desenvolvimento cultural. Para cerca de um terço dos entrevistados do estudo de Benkel et al. (2009a) a necessidade de suporte profissional aumentou com a proximidade da morte do paciente.

Na pesquisa de Grant, Brown, Leng, Bettega e Murray (2011) sobre os programas de Cuidados Paliativos em três diferentes regióes da África, ganhou destaque o fato de a equipe de Cuidados Paliativos 
ter levado às comunidades locais conhecimento especializado sobre a natureza e os efeitos de doenças, o que até então era ausente e reforçava a estigmatização das pessoas adoecidas. A presença destas equipes na comunidade mudou as atitudes em relação àqueles que estavam morrendo, permitindo que os familiares e os membros das comunidades promovessem cuidados mais abrangentes aos pacientes. Somado a isso, o auxílio da equipe de Cuidados Paliativos permitiu que os familiares pudessem cuidar do paciente em casa (Grant et al. 2011).

A Rede de Suporte Social também desempenhou a função de apoio emocional (1.1.2) que, segundo as pesquisas de Carlsson (2010) e Wong e Chan (2007) foi uma função importante para auxiliar aos familiares a lidar com situaçóes dolorosas durante o processo de cuidado. Sessenta e três por cento $(n=66)$ dos participantes do estudo de Götze, Brähler, Gansera, Polze e Köhler (2014) relataram ter recebido apoio psicossocial de seu médico de família. Apesar do destaque à função de apoio emocional desempenhada pelos profissionais, as pesquisas náo especificaram de que modo esse apoio foi fornecido aos familiares e que atividades eles desempenharam para tal. Observou-se que a disponibilidade da Rede de Suporte Social promoveu senso de segurança (1.1.3) (Benkel et al., 2009a) aos cuidadores, pois estes se sentiram seguros ao saber que os serviços de Cuidados Paliativos estavam disponíveis e também acolhidos por terem sido lembrados pelos profissionais durante o período de luto (Aoun, Rumbold, Howting, Bolleter \& Breen, 2017). Reitera-se que, segundo Ornelas (1997), a presença da Rede de Suporte Social é capaz de colaborar para o desenvolvimento do bem estar e para os sentimentos de autoestima e adaptação, promovendo mudanças no contexto situacional do indivíduo.

Os voluntários dos serviços de cuidados paliativos apareceram como importante Rede de Suporte por auxiliarem os cuidadores no processo de cuidado do paciente (MacLeod, Skinner \&, Low, 2012). $\mathrm{Na}$ África, os voluntários eram tidos como referência de cuidado, em especial pela sua proximidade com a comunidade (Grant et al., 2011). Segundo os familiares do estudo de Pesut et al. (2018), os voluntários detinham características como as de serem bons ouvintes, atenciosos, 
acolhedores, gentis e não intrusivos. Para estes cuidadores, os voluntários adquiriram um papel central nos cuidados ao paciente, de modo a se sentirem inseguros sem o auxílio dos voluntários. A concepção dos participantes a respeito dos voluntários se contrapóe a percepção em relação ao sistema de saúde, que foi percebido como frio e fragmentado. Embora eles reconhecessem as qualidades dos médicos da atenção primária, os familiares sentiam que eles não tinham tempo para ajudá-los a resolver seus conflitos (Pesut et al., 2018).

Nesse sentido, é possível perceber que há, por um lado, as funções de ajuda material e de serviços e de apoio emocional, que oferecem a sensação de segurança aos cuidadores, e, por outro, a sensação de um distanciamento em relação aos profissionais, percebidos como "frios". Assim, esses e outros sentimentos e percepçóes em relação à equipe de saúde são detalhados na subcategoria a seguir.

\subsection{Sentimentos e percepçóes em relaçáo aos profissionais de saúde}

A continuidade dos cuidados após a morte do paciente (1.2.2) foi um fator importante para o suporte aos familiares, como mencionado no estudo de Aoun et al. (2017). No referido estudo, os participantes expressaram a relevância da disponibilidade dos serviços de Cuidados Paliativos na vivência do luto, seja pelo contato telefônico ou por meio de visitas semanais após a morte do paciente, enquanto que alguns participantes referiram não terem recebido nenhum tipo de suporte ao luto. No período logo após a morte, os participantes do estudo de Benkel, Wijk e Molander (2009b) relataram o apoio dos profissionais principalmente no que tange ao apoio emocional. Na pesquisa de Benkel et al. (2009a), por sua vez, foi destacado o acesso a profissionais da psicologia e assistência social para aqueles cuidadores que precisaram de ajuda prolongada. Ressalta-se que as conclusóes de Wiese et al. (2010) apontaram o cuidado especializado de uma equipe de Cuidados Paliativos como um fator que auxiliou na redução de complicaçóes no luto dos familiares, uma vez que foi constatado que aqueles participantes que mantiveram a continuidade dos cuidados dos profissionais após a morte do paciente não apresentaram indícios de luto complicado. 
Por outro lado, evidenciou-se a ruptura (1.2.2) existente nos cuidados devido ao afastamento dos profissionais de saúde dos familiares após o óbito dos seus entes. Pais de crianças com doenças limitadoras relataram a sensação de terem sido "deixados de lado" pelos profissionais de saúde (Nicholas, Beaune, Barrera, Blumberg \& Belletrutti, 2016), o que gerou nos familiares um sentimento de abandono (1.2.3) após a morte dos filhos (Eskola, Bergstraesser, Zimmermann \& Cignacco, 2017). Isto indica uma descontinuidade do cuidado, diferente do que é prezado pelo conceito dos Cuidados Paliativos, ao destacar o suporte ao luto dos familiares após a morte do paciente (WHO, 2002).

Esse fator contribuiu para que o Suporte Social tenha sido considerado, em algumas situaçóes, insuficiente (1.2.4), o que deixou transparecer o sentimento dos familiares de insatisfaçáo com o apoio oferecido. Alguns pais (homens) de crianças com doenças limitadoras à vida consideraram que o sistema não oferecia suporte suficiente para o filho, para si e para sua família (Nicholas et. al, 2016), o que corrobora com os pais de outro estudo (Eskola et al., 2017), o qual enfatizou a ausência de serviços orientados para a assistência em casa como um obstáculo para os cuidados do filho. No estudo de Duggleby et al. (2010) os familiares relataram a falta de acessibilidade aos serviços de Cuidados Paliativos, enquanto alguns participantes do estudo de Wong e Chan (2007) não estavam satisfeitos com o tratamento dispendido aos pacientes pela equipe de saúde, principalmente pela falta de informaçóes relacionadas ao paciente, que por sua vez gerou o sentimento de preocupaçáo e desamparo.

Nessa direçáo, os familiares cuidadores de pacientes com tumor cerebral maligno, relataram não terem recebido toda ajuda necessária por parte dos serviços de Cuidados Paliativos em relação aos aspectos práticos do cuidado, ou, ainda, que as soluçóes propostas pelos profissionais não consideravam a singularidade de cada caso (Arber, Hutson, Vries \& Guerrero, 2013). Em relação à adequação dos serviços para as necessidades dos cuidadores, aponta-se que a resposta lenta de certos tipos de prestação de serviços, fez com que os familiares se sentissem sozinhos frente à crise o que, por sua vez, funcionou como potencializador 
de níveis de estresse (Williams et al., 2011). Da totalidade dos cuidadores de pacientes que receberam Cuidados Paliativos oncológicos, somente 5\% relataram ter recebido apoio psicológico profissional no mês anterior à pesquisa (Götze et al., 2014). Nesse sentido, o estudo de Collins et al. (2016) concluiu com base nas experiências descritas pelos pais, a necessidade de desenvolver um suporte mais efetivo que procure reduzir os impactos na saúde dos cuidadores nesse contexto.

Outro fator que contribuiu para a insatisfação dos cuidadores com o serviço de Cuidados Paliativos é a comunicação (1.2.5), pois para os familiares a comunicação com os profissionais da saúde adquiriu importância no processo de cuidado e fim de vida (Canaway et al., 2017). A comunicação adequada com a equipe e o fornecimento de informaçóes essenciais foi mencionada pelos familiares como fatores que os ajudaram a se adaptarem às transiçôes (Duggleby et al., 2010). Por outro lado, uma comunicação pouco desenvolvida com a equipe de saúde foi tema central nos dois países da África em que se fez a avaliação dos programas de Cuidados Paliativos. Evidencia-se falta de informaçóes acerca do estado de saúde do paciente e sobre o manejo dos sintomas, o que afetou a qualidade do cuidado que os membros da família puderam oferecer (Selman et al., 2009).

Nessa direção, os familiares chineses de pacientes em fim de vida, também insatisfeitos com as informaçôes concedidas, desejavam que a equipe de enfermagem fosse mais ativa ao contar sobre a condição de seu parente, pois acreditavam que se tivessem compreendido melhor a condição do paciente, suas preocupaçôes seriam reduzidas (Wong \& Chan, 2007). A falta de informação e as avaliaçóes negativas sobre a comunicaçáo com a equipe de saúde também estiveram presentes nos estudos de MacLeod, Skinner e Low (2012) e de Duggleby et al. (2010). Cabe mencionar que a comunicação é um dos aspectos centrais no contexto dos Cuidados Paliativos, bem como a deteç̧ão das necessidades da família, sendo necessária a informação adequada e a convocaçáo de fazer parte dos cuidados ao paciente, o que favorece a compreensão e o enfrentamento na experiência do cuidado (Silva \& Araújo, 2012). Nessa direção, a comunicação de notícias difíceis 
deve ser feita por meio de um trabalho interdisciplinar, de maneira cautelosa, ativa e centrada no vínculo. Assim, o apoio e orientação aos familiares são essenciais no contexto dos Cuidados Paliativos (Gomes \& Othero, 2016).

Os conteúdos presentes nesta categoria deram ênfase às funçóes desempenhadas pela equipe e o reconhecimento que os familiares tiveram pelo suporte social oferecido. A partir disso, é possível compreender que os profissionais dos Cuidados Paliativos auxiliaram os familiares frente ao processo de cuidado, durante o fim de vida do paciente e do luto. Há também o sentimento de insatisfação com os serviços, considerados insuficientes em sua tarefa de suporte e cuidado, tanto pela comunicação, por vezes falha, quanto pela ruptura do cuidado após a morte do paciente, $o$ que provocou um sentimento de abandono nos familiares.

\section{Redes Sociais Significativas nos cuidados paliativos}

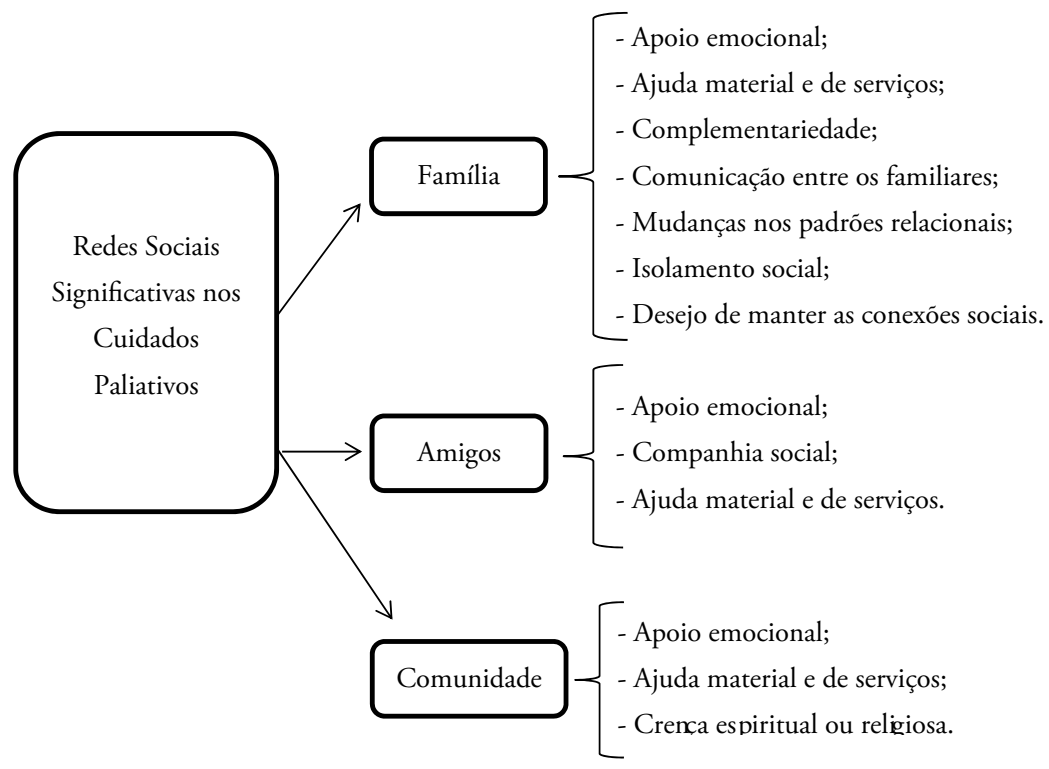

Figura 3. Principais resultados dos estudos: categoria 2, subcategorias e elementos de análise. 
Os estudos que constituem o corpus deste trabalho também trazem os familiares e amigos como principais fornecedores de apoio durante o processo de cuidado e de luto (Aoun et al., 2017; Arber et al., 2013; Benkel et al., 2009a; Eskola, et al., 2017; Götze et al., 2014; MacLeod et al., 2012; Monterosso, Kristjanson \& Phillips, 2009; Nicholas et al., 2016). Esses resultados podem ser entendidos no sentido de que as Redes Sociais Significativas, que são representadas por aquelas pessoas percebidas como importantes para o indivíduo, podem funcionar como promotoras de qualidade de vida frente a situaçóes de adoecimento (Sluzki, 1997). Segundo este autor, as relaçóes sociais são capazes de contribuir para o sentido da vida dos seus membros, estimulando o sentido de viver e favorecendo os comportamentos de cuidados de saúde e as atividades pessoais rotineiras. Ademais, a presença de figuras familiares é capaz de diminuir os níveis de ansiedade e de estresse (Sluzki, 1997). Tendo em vista que os familiares estão imersos nesse contexto, as suas redes sociais podem auxiliá-los nos cuidados dos pacientes e no cuidado de si, por meio do auxílio das atividades domésticas, conversas e apoio emocional.

\subsection{Família}

Quase a totalidade dos participantes (90\%) do estudo de Götze et al. (2014) sobre o estresse e a qualidade de vida dos familiares cuidadores de pacientes em Cuidados Paliativos disseram ter recebido ajuda da família no processo de cuidado, mas a pesquisa não deixa claro quais as modalidades de ajuda dispendida pela família, uma vez que ela se utiliza do termo "suporte social" de maneira ampla. Já no estudo de Benkel et al. (2009a), mais de 50\% dos entrevistados receberam apoio psicológico da família, o que inclui, segundo a definição dos autores, apoio emocional (2.1.1) e cognitivo. O apoio emocional foi caracterizado pela necessidade de conversar com outras pessoas durante o processo de luto, o que abarcava discutir assuntos diferentes com pessoas diversas para que a mesma pessoa náo precisasse ouvir sobre o mesmo assunto, havendo a preocupação de não sobrecarregar excessivamente sua rede (Benkel et al., 2009a). Nessa direção, destaca-se a 
importância de ter com quem conversar, pois para os participantes do estudo de Carlsson (2010) a companhia dos amigos e da família, em especial os netos, representaram um estímulo para que eles seguissem em frente. No estudo de Nicholas et al. (2016), os pais (homens) cuidadores destacaram o apoio das suas cônjuges como uma fonte de força, que os ajudou durante o adoecimento e morte do filho.

Os familiares foram um dos principais responsáveis não só pelo apoio emocional aos cuidadores, mas também pelo apoio prático (Arber et al., 2013), definido segundo a função de ajuda material e de serviços (2.1.2). As pessoas disponíveis, como os filhos ou o marido, para ajudar o cuidador principal com alguns dos deveres do cuidado ao paciente, representavam um fator facilitador da resiliência (Giesbrecht et al., 2015). Oitenta e sete por cento $(n=62)$ dos pais cuidadores de crianças que morreram com câncer disseram ter recebido suporte da família imediata ( $72 \%$ parceiros e $17 \%$ irmãos) e oitenta e dois por cento $(n=55)$ relataram ter recebido suporte da família extensa, $64 \%$ $(\mathrm{n}=44)$ de parentes próximos, o que os auxiliou na manutenção da rotina domiciliar (Monterosso et al., 2009). Os familiares também ofereceram ajuda material e de serviços quando obtinham conhecimentos especializados, ao pertencerem à área médica e auxiliarem no cuidado do paciente, o que é apontado como um fator que favoreceu a redução do estresse e da sobrecarga (Williams et al., 2011). Ainda, o suporte prático foi oferecido pelos membros das famílias e parentes por meio do auxílio nos aspectos legais e financeiros (Benkel et al., 2009a).

Em contrapartida, os cuidadores também relataram a ausência de apoio (2.1.3) por parte dos familiares, como é o caso de cuidadores de pacientes com tumor cerebral maligno, os quais mencionaram, por vezes, faltar suporte por parte dos membros da família, pois estes adotaram comportamentos evitativos, principalmente pela não compreensáo do que se tratava um tumor cerebral e das repercussóes geradas, o que proporcionou maior angústia e sofrimento emocional no cuidador principal (Arber et al. 2013). Segundo Sluzki (1997), o caráter aversivo da doença pode provocar um afastamento por parte dos membros das redes do indivíduo doente (Sluzki, 1997). Entende-se, 
nesse caso, que o movimento de afastamento inclui não só o paciente, mas todo o contexto envolto dele, o que abarca o cuidador.

A ausência de suporte ainda foi relatada quando os cuidadores estavam afastados da sua família de origem e não havia nenhum familiar próximo de onde eles moravam para ajudar na prestação de cuidados, ou o fato de não terem com quem conversar e dividir suas vivências. Esses fatores foram apontados como um dos principais contribuintes para o aumento do nível de estresse (Williams et al., 2011), enquanto no estudo de Song et al. (2011) a falta de suporte por parte da família foi associada com o aumento de pensamentos suicidas.

No caso em que as Redes Sociais Significativas dos familiares eram inexistentes, a Rede de Suporte Social funcionou de maneira complementar às Redes, ou seja, adquiriram a característica de complementariedade (2.1.3). Nesses casos, ficou clara uma maior necessidade do apoio profissional, quando comparado aos familiares que possuíam uma rede social com bom funcionamento (Benkel et al., 2009a). O estudo de Benkel et al. (2009b), cujos participantes eram cônjuges de pacientes que morreram na unidade de cuidados e buscou reconhecer as pessoas que precisavam de suporte especial de profissionais, indicou que um terço dos participantes precisou de algum tipo de ajuda profissional nos casos em que havia dificuldades emocionais em lidar com a situação, quando o enlutado não queria perturbar a sua rede, ou a sua família, por conta dos membros também estarem vivenciando o processo de luto (Benkel et al., 2009b). Nesse contexto, apesar da importância da comunicação entre os familiares (2.1.4), apontada pela pesquisa de Breen et al. (2017), no que tange a uma comunicação aberta com a pessoa que está adoecida ou em fim de vida, as falhas na comunicação, dificuldades de falar com a família e contar notícias a respeito foram frequentes (MacLeod et al., 2012).

Frente ao processo de cuidado, alguns pais relataram mudanças nos padrões relacionais (2.1.5), em que há uma diminuição da intimidade entre o casal (Nicholas et al., 2016), e alguns os cônjuges mencionaram ter havido mudanças de papéis, como, por exemplo, de esposa para enfermeira (Duggleby et al., 2010). Por outro lado, algumas esposas 
do estudo de Sutherland (2009) comentaram sobre o fato das relaçóes terem se tornado mais íntimas, especialmente devido a maior frequência de contato no cotidiano do cuidado. Nesse sentido, a experiência do cuidado pôde ser válida para o estreitamento dos laços familiares (Duggleby et al., 2010; Nicholas et al., 2016).

No que tange aos laços sociais, os cuidadores podem não ter contato social além da família imediata, o que leva a sensação de isolamento social (2.1.6) (Duggleby et al., 2010; Carlsson, 2010; Nicholas et al., 2016). Quando o paciente era uma criança, os filhos, por conta da fragilidade física, deixaram de ser convidados para ocasióes sociais, o que também fez com que os pais perdessem a oportunidade de interagir com outras famílias. Por vezes, esse movimento de afastamento partiu dos próprios pais por se sentirem como um "fardo" para os outros (Collins et al., 2016). Esse dado corrobora com o que aponta Sluzki (1997) sobre o impacto negativo do adoecimento nas redes sociais, pois a doença pode ter caráter limitante, além de impor restriçôes aos contatos sociais, e os indivíduos, por sua vez, tendem a ativar menos suas redes, o que contribui para redução do intercâmbio interpessoal (Sluzki, 1997). Transpóe-se para a situação dos cuidadores, que, envolvidos no contexto do adoecimento, têm menos oportunidades de interaçóes sociais, uma vez que a tarefa do cuidado exige seu envolvimento físico e afetivo.

Por outro lado, é possível que o processo de adoecimento gere novas redes, como os serviços sociais e de saúde (Sluzki, 1997), tal como indica o estudo de Collins et al. (2016), em que a experiência de cuidar dos filhos, para alguns pais, levou-os a construir uma nova rede com quem estivessem partilhando de situação semelhante. Os pais participantes da pesquisa relataram a experiência de dividir seu conhecimento para apoiar os outros. Nessa direçáo, apesar da sensação de isolamento social, alguns cuidadores relataram o desejo de manter as conexóes sociais (2.1.7), como, por exemplo, continuar frequentando o clube onde encontravam os amigos (Lewis, DiGiacomo, Currow \& Davidson, 2014). 
Diante disso, foi possível observar no conjunto de estudos analisados, que os familiares dos cuidadores principais adquiriram importância para o enfrentamento do processo de cuidado, desempenhando funçôes de apoio emocional e de ajuda material e de serviços. Houve também o sentimento de ausência de apoio de familiares e as mudanças nos padróes relacionais diante da tarefa do cuidado. Quando os cuidadores não tinham contato fora de sua família imediata, surgiu o sentimento de isolamento social e também o desejo de manter as conexóes fora desse círculo. Nesse sentido, os amigos podem figurar como importantes aliados para o enfrentamento, conforme descreve a próxima subcategoria.

\subsection{Amigos}

No estudo de Götze et al. (2014) os cuidadores entrevistados relataram que $70 \%$ da ajuda recebida durante o processo de cuidado foi originária dos amigos. Estes foram apontados como importantes fontes de apoio psicológico e social no estudo de Benkel et al. (2009a), pois os enlutados mencionaram falar sobre os assuntos difíceis mais com os amigos e colegas, do que com os familiares e parentes, o que aponta para a funçáo de apoio emocional (2.2.1) desempenhada pelos amigos e também de companhia social (2.2.2) ao estarem próximos e disponíveis para conversar, ou poder ir para o clube com eles, por exemplo (Williams et al., 2011).

Uma forma de apoio psicológico relatada por quase $50 \%$ dos entrevistados foi o suporte de alguém que já tivesse vivido a mesma situação, o que revela um sentimento de reciprocidade, pois o compartilhamento com pessoas que estavam passando por vivências parecidas levou muitos cuidadores a se sentirem aliviados (Benkel et al., 2009a). Os participantes do estudo de Arber et al. (2013) relataram a importância de ter um amigo ou alguém fora da situação familiar que compreendesse o que era ser um cuidador. Neste estudo, os cuidadores puderam participar de grupos de suporte no hospice, que proporcionava alívio de suas preocupaçóes em meio a pessoas que entendiam o que estavam passando (Arber et al., 2013). 
O sentimento de reciprocidade se manteve durante a vivência do luto para os cônjuges do estudo de Benkel et al. (2009b), que relataram preferir conversar com pessoas que já tivessem passado pela experiência do luto, pois poderiam melhor compreendê-los, assim como para os cônjuges do grupo de enlutados do estudo de Kögler, Brandl, Brandstätter, Borasio e Fegg (2013). O grupo propiciou o sentimento de pertença e união, favorecendo a expressão das emoções e sentimentos relacionados à vivência do luto e o alívio ao perceber que havia outros que experimentavam as mesmas situaçóes. Os pais da pesquisa de Nicholas et al. (2016) ainda mencionaram fazer uso da internet, por meio de grupos online de pais que estavam vivenciando situaçóes semelhantes.

Além da importância do apoio emocional citado no estudo de Eskola et al. (2017), há o destaque para ajuda material e de serviços (2.2.3), quando os amigos auxiliaram a cuidar dos irmãos da criança adoecida e cozinhavam para a família, o que permitia que os pais estivessem mais tempo com seus filhos. Alguns amigos auxiliavam a, por exemplo, cortar a grama da casa (Williams et al., 2011), ou no reconhecimento dos direitos do cuidador, no acesso ao serviço e a benefícios, o que proporcionou uma "folga do papel de cuidador" e promoveu maior qualidade de vida (Arber et al., 2013). Essa função de apoio social desempenhada pelos amigos foi apontada no estudo de Williams et al. (2011) como importantes mecanismos para reduzir o estresse e a sobrecarga. Entretanto, muitos participantes não tiveram suas expectativas atendidas em relação à ajuda prática que esperavam receber dos seus amigos (Benkel et al., 2009a).

Observou-se assim nos estudos analisados que os amigos foram membros das redes sociais significativas dos cuidadores que desempenhavam as funçóes de apoio emocional e companhia social ao estarem próximos e disponíveis para a escuta e compartilhamento das vivências dos familiares. A ajuda material e de serviços foi oferecida desde tarefas básicas, como cozinhar ou cuidar dos filhos, ao reconhecimento e ajuda para o acesso aos direitos dos familiares enquanto cuidadores, o que auxiliou na diminuição do sentimento de estresse e sobrecarga. 


\subsection{Comunidade}

$\mathrm{O}$ valor da conexão com a comunidade foi destacado nos estudos da presente categoria. Os membros da comunidade, como os vizinhos, foram importantes ao oferecer apoio emocional (2.3.1), por meio de conversas (MacLeod et al., 2012), suprindo os cuidados e necessidades sociais dos cuidadores, ou ao fornecendo ajuda material e de serviços (2.3.2), ao cortar a grama de suas casas e preparar as refeiçóes (Lewis et al., 2014). O suporte prático oferecido pelos vizinhos, a disponibilidade de irem até o paciente quando ele precisava, e o fato de eles saberem como proceder no caso de alguma intercorrência com o paciente, permitiu que os cuidadores pudessem trabalhar em tempo parcial (Arber et al., 2013).

$\mathrm{Na}$ Uganda, os grupos comunitários auxiliaram na promoção dos cuidados pessoais, no acesso e apoio ao tratamento e suporte à subsistência, pois fomentaram o desenvolvimento de habilidades que permitiram a geraçáo de renda e o sustento de familiares. Por meio do cuidado das crianças após a morte dos pais, ajudando, especialmente, às viúvas e seus filhos, foi possível promover o suporte ao luto dos familiares (Mburu et al., 2013). Outro estudo desenvolvido na Uganda e África do Sul destacou a relevância do auxílio dos vizinhos, os quais provinham suporte e informação em relação à doença e seu manejo (Selman et al., 2009).

A crença espiritual ou religiosa (2.3.3) figurou como importante estratégia de enfrentamento da doença e morte (Nicholas et al., 2016) e auxiliou alguns cuidadores a manterem suas esperanças para cumprir suas funçóes de cuidado (Williams et al., 2011). É relevante destacar que a espiritualidade/religiosidade é uma ferramenta detentora de um arcabouço de explicaçôes, que, por sua vez, auxilia na atribuição de significado da doença e da morte, ainda, fomenta a esperança, motivação e oferece apoio emocional (Bousso et al., 2011).

A oração, por sua vez, representou uma maneira especial de honrar o relacionamento entre paciente e cuidador. Os participantes relataram sobre o valor da comunidade da igreja na prestaçáo de apoio social em 
suas vidas (Elliott, Gessert, Larson \& Russ, 2012). As igrejas locais e chefes de aldeias na Uganda, Kenya e Malawi favoreceram a aceitação em relação ao serviço de cuidados paliativos, pois incluíram o tema dos cuidados paliativos durante o culto (Grant et al., 2011). No entanto, nem sempre as experiências com a igreja foram positivas, tendo sido algumas estressantes, pois, por vezes, os participantes sentiram um rompimento na relação de confiança (Elliott et al., 2012).

Nessa direção, constatou-se nos estudos que as pessoas da comunidade funcionaram como importantes aliadas dos cuidadores ao estarem próximas e auxiliarem nas tarefas rotineiras, ou mesmo na atenção ao paciente, permitindo que os familiares cuidadores pudessem exercer outras atividades para além do cuidado. Ainda, o auxílio da comunidade foi prestado, inclusive, no suporte ao luto, por meio do cuidado das crianças, o que favoreceu que o enlutado vivenciasse seu processo de elaboração da perda.

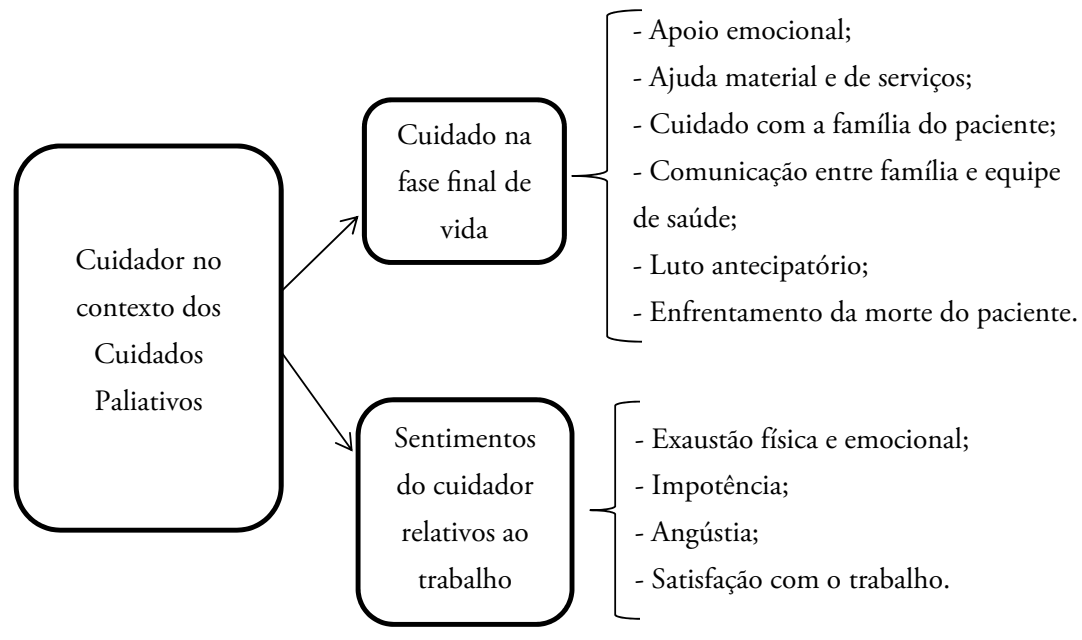

Figura 4. Principais resultados dos estudos: categoria 3, subcategorias e elementos de análise. 
No fim de vida do paciente, há a realização de uma gama de tarefas de cuidados que se estendem desde o cuidado físico e emocional do paciente, os serviços domésticos, até a gestão financeira da família (Gott, Wiles, Moeke-Maxwell, Black, Williams, Kerse \& Trussardi, 2018). Os cuidadores familiares da pesquisa de Williams et al. (2011), reforçaram os resultados mencionados, ao trazerem uma série de estressores em relação ao cuidado, como, por exemplo: responsabilidades de assistência em um contexto altamente emocional, a negociação de obrigaçóes e licenças de emprego e o gerenciamento dos custos financeiros associados ao cuidado. Portanto, são explorados, a seguir, os aspectos relacionados ao cuidado no fim de vida e os sentimentos do cuidador relativos à tarefa de cuidar.

\subsection{Cuidado na fase final de vida}

Os familiares, responsáveis pelo cuidado do ente enfermo, situaram a importância de receber apoio emocional (3.1.1) da família, amigos, colegas e de outros serviços, como os religiosos, pois este foi pontado como facilitador perante a experiência do cuidado no fim de vida (Canaway et al., 2017). Para os familiares do estudo de Wong e Chan (2007), o apoio psicossocial das enfermeiras foi muito importante diante da vivência de presenciar o familiar morrendo.

Frente aos cuidados de fim de vida, os familiares também destacaram a importância de ter suas necessidades práticas (3.1.2 Ajuda material e de serviços) atendidas diante da proximidade da morte, tais como: o auxílio no cuidado ao paciente, tanto no que se refere ao apoio do cuidado da enfermagem, do serviço social ou da família (Canaway et al., 2017) e orientaçôes relativas aos arranjos financeiros e funerários (Breen et al., 2017). Destacam-se, ainda, as figuras dos empregadores, possibilitando o tempo de afastamento do trabalho quando necessário (Canaway et al., 2017).

No cuidado com a família do paciente (3.1.3), membros da família descreveram que precisavam de cuidados e simpatia por parte da equipe (Wong \& Chan, 2007). Os participantes do estudo de Carlsson (2010) expressaram seu desejo de receber suporte emocional da equipe de saúde 
e sugeriram que ela promovesse o suporte psicossocial, o que incluía o apoio emocional e a necessidade de ter ajuda material e de serviços, a acessibilidade para falar com os profissionais e recursos comunitários. Já os pais do estudo de Monterosso et al. (2009) elegeram algumas necessidades frente ao cuidado na fase final de vida do filho, tais como: conhecer as maneiras de mantê-lo confortável, poder auxiliar nos métodos de controle da dor, receber visitas domiciliares de profissionais de saúde, sentir que os profissionais de saúde se preocupavam com o filho e estavam disponíveis para sanar suas dúvidas e ser instruído a respeito de qual tratamento o filho estava recebendo e seus efeitos. No estudo de Breen et al. (2017) os participantes relataram a necessidade de que serviço de Cuidados Paliativos focassem na pessoa como um todo e de que fossem desenvolvidos desde o período inicial da doença.

Em relação à comunicação entre família e equipe de saúde (3.1.4) foram destacados aspectos relativos à informação quanto à proximidade da morte. As cônjuges da pesquisa de Benkel et al. (2009b) mencionaram que ser informadas antes da morte é essencial para entender o que está acontecendo e para auxiliar na preparaçáo para a aproximação da morte do paciente (Benkel et al., 2009b). Nessa direção, os familiares do estudo de Wong e Chan (2007) frisaram a importância das enfermeiras terem informado quando a morte estava próxima a acontecer, porque isso lhes possibilitou estar junto do seu familiar no momento da morte. Os cuidadores familiares precisavam de informaçóes que os preparassem para apoiar o paciente que está morrendo, o que inclui a disponibilidade de cuidados práticos e estratégias para minimizar o sofrimento psicológico (Götze et al., 2014).

Cabe destacar que estudiosos do tema apontam esses elementos como importantes durante a experiência do Luto antecipatório (3.1.5), processo vivenciado frente à iminência de uma perda significativa, antes da perda real, que consiste na vivência dos momentos que antecedem a morte, junto às perdas inerentes desse período (Franco, 2014; Overton \& Cottone, 2016). Os pais de crianças com doenças limitadoras vivenciaram o luto antecipatório em relação à perda iminente do filho, somado às perdas pessoais, associadas à incapacidade de viver a 
vida como imaginaram (Collins et al., 2016). Na mesma direção, as esposas de pacientes com câncer experimentaram os sentimentos de remorso, arrependimentos e de solidão ao vislumbrar um futuro sem seus maridos (Sutherland, 2009) e os familiares chineses vivenciaram os sentimentos de raiva, tristeza e aceitação (Wong \& Chan, 2007). O estudo de Burke et al. (2015) fez a relação entre o apoio social insuficiente e a dificuldade da vivência do luto antecipatório. Neste estudo os cuidadores destacaram a importância da privacidade para estar com a pessoa querida em um local agradável e saber, previamente, o que o paciente desejava para sua morte e após ela, ou seja, apontava para a relevância de ter conversado sobre os desejos da pessoa, como o que fazer com o seu dinheiro e com seus pertences, o que foi apontado como um elemento que alivia o sentimento de culpa (Canaway et al., 2017).

Os fatores ligados ao luto antecipatório estão associados à experiência do luto pós-morte, pois poder resolver conflitos e questóes pendentes, conversar abertamente com o paciente sobre seus desejos, favorece a prevenção do luto complicado (Franco, 2014). Quanto mais os familiares puderem extravasar seu pesar, melhor poderão elaborar e suportar o seu luto após a morte (Kübler-Ross, 1981). Em relação ao enfrentamento da morte do paciente (3.1.6) no estudo de Eskola et al. (2017) as maiores necessidades apontadas pelos pais, para além da ajuda prática nos serviços domésticos, foi o suporte ao luto. O suporte ao luto foi promovido pela comunidade, ao cuidar das crianças após a morte de um dos pais (Mburu et al., 2013), pela equipe de saúde, ao fazer contato pessoal ou telefônico (Aoun et al., 2017; Wiese et al., 2010), pelos amigos e familiares, ao estarem disponíveis para conversas (Benkel et al., 2009a) e por aqueles (amigos, familiares, colegas de grupo) que já haviam passado por situação semelhante, através do compartilhamento e reciprocidade (Arber et al., 2013; Benkel et al., 2009a; Benkel et al., 2009b; Collins et al., 2016; Nicholas et al., 2016).

Os fatores destacados pelos familiares como importantes para serem atendidos, tais como o apoio emocional frente aos sentimentos que emergiram no processo de fim de vida, e aspectos da ordem prática, como a ajuda material e de serviços diante de orientaçóes e do cui- 
dado do paciente, apontam para diferentes aspectos que se conjugam no processo de luto antecipatório e que, dependendo da intensidade dos mesmos, poderão ser promotores ou dificultadores dos processos de elaboração do luto e cuidados em final de vida. Nesse processo, a vivência do luto antecipatório permite a construção de significados perante a perda e a sua vivência favorece a prevenção de complicaçóes na experiência do luto pós-morte. Diante disso, ressalta-se a importância dos vínculos significativos e da preparação dos profissionais de saúde para facilitar a vivência dos processos de fim de vida junto ao ente querido, assim como após a sua perda.

\subsection{Sentimentos do cuidador relativos ao trabalbo de cuidar}

A tarefa de cuidar de um paciente em Cuidados Paliativos pode levar os cuidadores à exaustáo física e emocional (3.2.1), conforme os estudos de (Carlsson, 2010; Eskola et al., 2017; MacLeod et al., 2012; Nicholas et al., 2016). Houve relatos de desgaste mental e emocional e um discurso tomado por sentimentos de exaustáo e tensão frente às exigências de cuidado (Nicholas et al., 2016). Para os cuidadores do estudo de Carlsson (2010), a exaustão está relacionada às preocupaçóes, incertezas e ao sofrimento do paciente. Os familiares relatam sobrecarga em relação às atividades (Eskola et al., 2017), estresse, desafios emocionais, tendo essa experiência sido comparada a uma "montanha-russa de emoções" (MacLeod et al., 2012). A sobrecarga poderia estar associada à falta de apoio emocional, ou seja, de alguém disposto a escutar suas questóes (Williams et al., 2011). Os aspectos relativos ao trabalho também provocaram sintomas físicos, como: dor de estômago, tontura, náusea, insônia, dificuldade de concentração e irritação (Carlsson, 2010). Observou-se que alguns sintomas emocionais e físicos perduraram inclusive após a morte do paciente (Williams et al., 2011).

Esses sentimentos, por sua vez, geraram um impacto negativo na saúde do cuidador. As participantes do estudo de Sutherland (2009) negligenciaram sua própria saúde para cuidar de seus cônjuges e para elas havia um senso de dever de cuidar do paciente. Outros familiares também relataram ter que deixar suas próprias necessidades de lado em 
prol do cuidado do ente enfermo (Carlsson, 2010), o que, para alguns cuidadores, levou a um sentimento de interrupção de suas próprias vidas (Duggleby et al., 2010). Nos cuidadores de pacientes com câncer foram constatadas limitaçôes em seu bem estar emocional, como sintomas graves de ansiedade e depressão, afetando, aproximadamente $33 \%$ e $28 \%$ dos participantes, respectivamente. Quanto à qualidade de vida dos cuidadores, esta foi significativamente menor do que na população geral (grupo controle) (Götze et al., 2014). A pesquisa de Monterosso et al. (2009) trouxe resultados semelhantes: 50\% dos pais de crianças que morreram com câncer sofreram de ansiedade severa, $32 \%$ de ansiedade moderada, $42 \%$ dos pais sofreram de depressão grave e $27 \%$ de depressão moderada.

Maior nível de sofrimento psíquico foi relacionado com a sobrecarga financeira devido ao fato do paciente ser o cônjuge do cuidador e com a falta de apoio social. Os cuidadores familiares que perceberam menos este apoio relataram níveis mais elevados de ansiedade e depressão (Götze et al., 2014). Os impactos na vida do cuidador repercutiram na vida familiar que, segundo os participantes, tornou-se frágil (Eskola et al., 2017), pois a doença afetou a toda família, por vezes causando atritos, como relatado pelos participantes do estudo de Arber et al. (2013). Reitera-se que, segundo Rolland (1995), o adoecimento crônico e a morte são considerados eventos impredizíveis dentro do fluxo horizontal de ansiedade e se constituem como estressoras do sistema familiar.

Os pais (homens) relataram sentimento de impotência (3.2.2) ao se perceberem incapazes de proteger e defender seu filho (Nicholaset al., 2016). A angústia (3.2.3) da família esteve presente frente às condiçóes de cuidado do paciente, pois a qualidade do atendimento pareceu causar impacto nos cuidadores que temiam que o paciente estivesse sentindo dor, sofrimento, ou em relação à dignidade do paciente e atenção dispendida pelos profissionais (Canaway et al., 2017). Também foi mencionado o sentimento de desamparo ao querer auxiliar na diminuição do sofrimento do paciente, mas não saber como (Wong \& Chan, 2007). Ao mesmo tempo em que exaustiva, houve relatos de 
satisfação com o trabalho (3.2.4), uma vez que a experiência de cuidar de um familiar figurou como gratificante e recompensadora (Williams et al., 2011; MacLeod et al., 2012; Grant et al., 2011). As esposas dos pacientes, por exemplo, relataram ter encontrado sentido para própria vida ao cuidar do parceiro (Sutherland, 2009).

Assim, observou-se nos estudos analisados que o cuidador no contexto dos Cuidados Paliativos enfrenta uma série de demandas relativas ao cuidado, que pode os levar à exaustão física, mental e emocional e desencadear impactos e agravamento na sua saúde, tal como sintomas de ansiedade e depressão. Acompanhar o ente enfermo no processo de fim de vida, não poder protegê-los e temer pelo seu sofrimento levaram aos sentimentos de angústia, desamparo e impotência. Nesse sentido, entende-se que o modo como o luto antecipatório é vivenciado, o suporte ofertado pelos amigos, familiares e profissionais da saúde e a maneira como ocorre o processo de adoecimento e atenção ao paciente, são fundamentais para o enfrentamento da perda.

\section{Consideraçóes finais}

O presente artigo buscou caracterizar as funçóes dos membros das redes sociais configuradas em torno de familiares de pacientes em Cuidados Paliativos, o que permitiu identificar uma distribuição de 30 publicaçóes regulares entre os anos de 2007 e 2018 e houve prevalência de pesquisas qualitativas. $\mathrm{O}$ maior número de publicações está concentrado nos países desenvolvidos e nenhum estudo ocorreu no contexto brasileiro e latino americano como um todo, o que evidencia uma lacuna na produção de conhecimento no Brasil e demais países da América Latina. A lacuna de estudos científicos da temática do presente estudo vai de encontro a crescente necessidade de produção de conhecimento acerca dos Cuidados Paliativos, uma vez que as doenças crônicas figuram como principais causa de morte na América Latina.

Mesmo que a busca por artigos empíricos tenha ocorrido em diferentes bases de dados e que o tempo de publicaçóes foi de 10 anos, essas 
condições podem ser consideradas limitações para este estudo. Assim, sugere-se que novas revisóes sejam realizadas em outras bases de dados, em período de tempo maior e que considere teses, dissertaçóes e livros que possam contribuir com a análise do estado da arte sobre o tema em questão.

A partir da revisão realizada, foi possível identificar que os familiares atuam ativamente no cuidado ao paciente, abrindo mão do seu próprio bem-estar, gerando impactos na sua saúde física e mental. Há relatos de sentimentos de exaustão e de sobrecarga e destaque para a importância da sua rede social e do suporte dos profissionais como importantes ferramentas no processo de cuidar e do luto.

O suporte social dos profissionais pode funcionar como um elemento facilitador da vivência do adoecimento, ao levar em consideração aspectos relativos ao cuidado do sofrimento do paciente, que aflige os cuidadores, a comunicação clara de informaçôes a respeito do estado de saúde, dos procedimentos realizados e da proximidade da morte. É preciso que haja cuidado e atenção aos familiares, colocando-se disponíveis para o esclarecimento de dúvidas e para o acolhimento durante o luto.

Conforme foi mostrado nos resultados deste estudo, as redes sociais significativas dos familiares, como os amigos, a família e os grupos comunitários os auxiliaram por meio do cuidado ao paciente, que, por sua vez, permitia que os cuidadores realizassem outras atividades e mantivessem certo senso de normalidade em suas vidas, a disponibilidade para as conversas e o compartilhamento. Cabe resgatar os dados dos estudos que apontam para a presença de voluntários nas comunidades, o que pode estar relacionada a uma questão cultural. Ainda, os trabalhos destacam a rede comunitária como uma rede que presta apoio ao enlutado, fato que é, de certo modo, não reconhecido na área da saúde. Nesse sentido, sinaliza-se para a importância da capacitaçáo das equipes de saúde da família para acolher os processos de luto da família na comunidade.

Os estudos indicaram para funçôes desempenhadas pelas redes, mas não houve especificação de quais atividades os membros das mesmas realizavam para promover o apoio emocional, de material e 
serviços, entre outras, aos familiares, o que indica para a necessidade de outros estudos que aprofundem a participação e influência das redes sociais no contexto de Cuidados Paliativos. Isto auxiliaria a produzir subsídios teóricos que possam contribuir como recursos para a intervenção dos profissionais de saúde, considerando as pessoas das redes como corresponsáveis dos pacientes enfermos nos Cuidados Paliativos e seus familiares.

\section{Referências}

Aoun, S.M., Rumbold, B., Howting, D., Bolleter, A. \& Breen, L. J. (2017). Bereavement support for family caregivers: The gap between guidelines and practice in palliative care. PLoS ONE, 12(10). https://doi.org/10.1371/journal.pone.0184750

Arber, A., Hutson, N., Vries, K. \& Guerrero, D. (2013). Finding the right kind of support: A study of carers of those with a primary malignant brain tumour. European Journal of Oncology Nursing 17, 52-58. https://doi.org/10.1016/j.ejon.2012.01.008

Benkel, I., Wijk, H. \&Molander, U. (2009a). Family and friends provide most social support for the bereaved. Palliative Medicine, 23, 141-149. https://doi.org/10.1177/0269216308098798

Benkel, I., Wijk, H. \&Molander, U. (2009b). Managing Grief and Relationship Roles Influence Which Forms of Social Support the Bereaved Needs. American Journal of Hospice \& Palliative Medicine, 26 (4). https://doi.org/10.1177/1049909108330034

Bousso, R. S., Poles, K., Serafim, T. de S. \& Miranda, M. G. de. (2011). Crenças religiosas, doença e morte: perspectiva da família na experiência de doença. RevEscEnferm USP, 45(2), 397-403. https://doi.org/10.1590/S0080-62342011000200014

Braz, M. S. \& Franco, M. H. P. (2017). Profissionais Paliativistas e suas Contribuiçóes na Prevenção de Luto Complicado. Psicologia: Ciência e Profissão, 37(1), 90-105. https://dx.doi.org/10.1590/ 1982-3703001702016 
Breen, L. J., Aoun, S. M., Rumbold, B., McNamara, B., Howting, D. A. \& Mancini, V. (2017). Building Community Capacity in Bereavement Support: Lessons Learnt From Bereaved Caregivers. American Journal of Hospice \& Palliative Medicine, 34(3), 275-281. https://doi.org/10.1177/1049909115615568

Burke, L. A., Clark, K. A., Ali, K. S., Gibson, B. W.,Smigelsky, M. A. \& Neimeyer, R. A. (2015). Risk Factors for Anticipatory Grief in Family Members ofTerminally Ill Veterans Receiving Palliative Care Services, Journal of Social Work in End-of-Life \& Palliative Care, 11(3-4), 244-266., https://doi.org/10.1080/155 24256.2015.1110071

Canaway, A., Al-Janabi, H., Kinghorn, P., Bailey, C. \& Coast, J. (2017). Development of a measure (ICECAP-Close Person Measure) through qualitative methods to capture thebenefits of end-of-life care to those close to the dying for use in economic evaluation. Palliative Medicine, 31(1), 53-62. https://doi. org/10.1177/0269216316650616

Carlsson, M. E. (2010). The significance of fatigue in relatives of palliative patients. Palliative and Supportive Care, 8, 137-142. https://doi.org/10.1017/S1478951509990885

Collins, A., Hennessy-Anderson, N., Hosking, S.,Hynson, J., Remedios, C. \& Thomas, K. (2016).Lived experiences of parents caring for a child with a life-limiting condition in Australia: A qualitative study. Palliative Medicine, 30(10), 950-959. https:// doi.org/10.1177/0269216316634245

Duggleby, W. D., Penz, K. L., Goodridge, D. M., Wilson, D. M., Leipert, B. D., Berry, P. H., Keall, S. R. \& Justice, C. J. (2010). The transition experience of rural older persons with advanced cancer and their families: a grounded theory study. $B M C$ Palliative Care, 9(5). https://doi.org/10.1186/1472-684X-9-5

Elliott, B., Gessert, C., Larson, P. \& Russ, T. (2012). Religious Beliefs and Practices in End-StageRenal Disease: Implications for Clinicians. Journal of Pain and Symptom Management, 44(3), 400-409. https://doi.org/10.1016/j.jpainsymman.2011.09.019 
Eskola, K.,Bergstraesser, E., Zimmermann, K. \& Cignacco, E. (2017) Maintaining family life balance while facing a child's imminent death-A mixed methods study. J Adv Nurs,73, 2462-2472. https://doi.org/10.1111/jan.13304

Franco, M. H. P. (2014). Luto antecipatório em cuidados paliativos. En: M. H. P. Franco \& K. K. Polido (Ed.). Atendimento psicoterapêutico no Luto (pp.26-35). São Paulo: Zagodoni.

Giesbrecht, M., Wolse, F., Crooks, V. \& Stajduhar, K. (2015). Identifying socio-environmental factors that facilitate resilience among canadian palliative family caregivers a qualitative case. Palliative and Supportive Care, 13, 555-565. https://doi.org/ $10.1017 /$ S 1478951513001028

Gomes, A. L. Z. \& Othero, M. B. (2016). Cuidados paliativos. Estudos Avançados, 30(88), 155-166. https://doi.org/10.1590/ s0103-40142016.30880011

Gott, M., Wiles, J., Moeke-Maxwell, T., Black, S., Williams, L., Kerse, N. \&Trussardi, G. (2018). What is the role of community at the end of life for people dying in advanced age? A qualitative study with bereaved family carers. Palliative Medicine, 32(1) 268-275. https://doi.org/10.1177/0269216317735248

Götze, H., Brähler, E.,Gansera, L., Polze, N. \& Köhler, N. (2014). Psychological distress and quality of life of palliative cancerpatients and their caring relatives during home care. Support Care Cancer, 22, 2775-2782. https://doi.org/10.1007/ s00520-014-2257-5

Grant, L., Brown, J., Leng, M., Bettega, N. \& Murray, S. (2011). Palliative care making a difference in rural uganda, kenya and malawi three rapid evaluation field studies. Palliative Care, 10(8). https://doi.org/10.1186/1472-684X-10-8

Gupta, V. \& Prescott, H. (2012). “That must be so hard” examining the impact of childrens palliative care services on the psychological wellbeing of parents. Clinical Child Psychology and Psychiatry, 18(1) 91-99. https://doi.org/10.1177/1359104512448146 
Kögler, M.K., Brandl, J., Brandstätter, M., Borasio, G. D. \& Fegg, M.J. (2013). Determinants of the Effect of Existential Behavioral Therapy for Bereaved Partners A Qualitative Study. Journal of Palliative Medicine, 16(11). https://doi.org/10.1089/ jpm.2013.0050

Kübler-Ross, E. (1981). Sobre a morte e o morrer: O que os doentes terminais têm para ensinar a médicos, enfermeiras, religiosos e aos seus próprios parentes. São Paulo: Martins Fontes.

Lewis, J. M., DiGiacomo, M., Currow, D. \& Davidson, P. (2014). Social capital in a lower socioeconomic palliative care population: a qualitative investigation of individual, community and civic networks and relations. BMC Palliative Care, 13, 3(30). https:// doi.org/10.1186/1472-684X-13-30

MacLeod, A., Skinner, M. \& Low, E. (2012). Supporting hospice volunteersand caregivers through community-based participatory research. Health and Social Care in the Community, 20(2), 190-198. https://doi.org/10.1111/j.1365-2524.2011.01030.x

Mburu, G., Oxenham, D., Hodgson, I., Nakiyemba, A., Seeley, J. \& Bermejo, A. (2013). Community Systems Strengthening for HIV Care: Experiences From Uganda. Journal of Social Work in End-Of-Life \& Palliative Care, 9(4), 343-368, https://doi.org/1 $0.1080 / 15524256.2013 .846889$

Monterosso, L., Kristjanson, L. J. \& Phillips, M. B. (2009). The supportive and palliative care needs of Australian families of children who die from cancer. Palliative Medicine, 23, 526-536. https://doi.org/10.1177/0269216309104060

Nicholas, D. B., Beaune, L., Barrera, M., Blumberg, J. \& Belletrutti, M. (2016) Examining the Experiences of Fathers of Children with a Life-Limiting Illness. Journal of Social Work in End-of-Life \& Palliative Care, 12 (1-2), 126-144, https://doi.org/10.1080/1 5524256.2016 .1156601

Olabuénaga, J. I. R. (2009). Metodología de la investigación cualitativa. Bilbao: Universidad de Deusto. 
Organização Mundial da Saúde (2015). Resumo do Relatório Mundial de Envelhecimento e Saúde. Geneva: World Health Organization.

Organização Pan-Americana da Saúde (2017). Resumo do panorama regional e perfil do Brasil. Washington, DC: Pan American Health Organization /World Health Organization.

Ornelas, J. (1997). Psicologia Comunitária: origens, fundamentos e áreas de intervenção. Análise Psicológica, 3(15), 375-388.

Ornelas, J. (2008). Psicologia Comunitária. Lisboa: Fim de século.

Overton, B. L. \& Cottone, R. R. (2016). Anticipatory Grief: A Family Systems Approach. The Family Journal: Counseling and Therapy for Couples and Families, 24(4), 430-432. https://doi. org/10.1177/1066480716663490

Pan American Health Organization (2007). Health in the Americas. Washington, DC: Pan American Health Organization /World Health Organization.

Pesut, B., Duggleby, W., Warner, G., Fassbender, K., Antifeau, E., Hooper, B., Greig, M. \& Sullivan, K. (2018). Volunteer navigation partnerships: Piloting a compassionate community approach to early palliative care. BMC Palliative Care, 17(2), pp. https://doi.org/10.1186/s12904-017-0210-3

Rolland, J. S. (1995). Doença Crônica e o Ciclo de Vida Familiar. En: B. Carter \& M. MacGoldrick (Eds.), As mudanças no ciclo de vida familiar: uma estrutura para a terapia familiar (2a ed.) (pp. 393-408). Porto Alegre: Artmed

Selman, L., Higginson, I. J.,Agupio, G.,Dinat, N., Downing, J., Gwyther, L.,Mashao, T., Mmoledi, K., Moll, A. P., Sebuyira, L. M., Panajatovic, B. \& Harding, R. (2009). Meeting information needs of patients with incurable progressive disease and their families in South Africa and Uganda: multi centre qualitative study. BMJ, 338. https://doi.org/10.1136/bmj.b1326

Silva, M. J. P. \& Araújo, M. M. T. (2012). Comunicação em Cuidados Paliativos. En: R. T. Carvalho \& H. A. Parsons (Eds.), Manual de Cuidados Paliativos ANCP (2a ed.) (pp. 75-85). Porto Alegre, RS: Sulina. 
Sluzki, C. E. (1997). A rede social na prática sistêmica: alternativas terapêuticas. São Paulo: Casa do Psicólogo.

Song, J. I., Shin, D. W., Choi, J. Y., Kang, J., JiBaik, Y., Mo, H., Park, M. H., Choi, S. E., Kwak, J. H. \& Kim, E. J. (2011). Quality of life and mental health in family caregivers of patients with terminal cancer. Support Care Cancer, 19, 1519-1526. https:// doi.org/10.1007/s00520-010-0977-8

Sutherland, N. (2009). The meaning of being in transition to end-oflife care for female partners of spouses with cancer. Palliative and Supportive Care, 7, 423-433. https://doi.org/10.1017/ S1478951509990435

Torraco, R. J. (2005). Writing Integrative Literature Reviews: Guidelines and Examples. Human Resource Development Review, 4(3), 356-367. https://doi.org/10.1177/1534484305278283

Wiese, C. H. R., Morgenthal, H. C., Bartels, U. E., Voßen-Wellmann, A., Graf, B. M. \& Hanekop, G. G. (2010). Post-mortal bereavement of family caregivers in Germany: a prospective interview-based investigation. Wien Klin Wochenschr, 122, 384-389. https://doi.org/10.1007/s00508-010-1396-z

Williams, A. M., Eby, J. A., Crooks, V. A., Stajduhar, K., Giesbrecht, M., Vuksan, M., Cohen, S. R., Brazil, K. \& Allan, D. (2011). Canada's Compassionate Care Benefit: Is it an adequate public health response to adressing the issue of caregiver burden in end-of-life care? BMC Public Health, 11, 335. https://doi.org/ 10.1186/1471-2458-11-335

Wong, M. \& Chan, S. (2007).The experiences of Chinese family members of terminally ill patients - a qualitative study. Journal of Clinical Nursing, 16, 2357-2364. https://doi.org/10.1111/ j.1365-2702.2007.01943.x

World Health Organization. (2002). National cancer controlprogrammes: policies and managerial guidelines ( $2^{\mathrm{a}} e d$.). Geneva: World Health Organization.

World Health Organization. (2014). Global status report on noncommunicable diseases. Geneva: World Health Organization. 
Redes sociais nos cuidados paliativos: uma revisão integrativa da literatura / Reis et al.

World Health Organization. (2016). World Health Statistics 2016: Monitoring health for the Sustainable Development Goals. Geneva: World Health Organization.

Worldwide Palliative Care Alliance. (2014). Global Atlas of Palliative Care at the End of Life. Geneva: World Health Organization.

Recibido: 15 de noviembre, 2018 Revisado: 2 de setiembre, 2019 Aceptado: 23 de setiembre, 2019 